\title{
Wave hydrodynamic forces over mooring lines on Floating Offshore Wind Turbines
}

\author{
Pau Trubat*1, Climent Molins ${ }^{1}$, Xavi Gironella $^{1}$ \\ pau.trubat.casal@upc.edu, climent.molins@upc.edu, xavi.gironella@upc.edu \\ 1. Department of Civil and Environmental Engineering, Universitat Politècnica de Catalunya (UPC BarcelonaTech), \\ C/Jordi Girona 1-3, 08034, Barcelona, Spain \\ * Corresponding author
}

\section{Keywords:}

FOWT; floating; wind turbine; mooring; wave forces; fatigue

\begin{abstract}
The mooring loading of floating offshore wind turbines are mainly induced by the platform motions through the fairleads. The dynamic analysis usually only considers the hydrodynamic forces over the mooring by the motion of the line disregarding the wave loads. Using the FloaWDyn aero-servo-hydro-elastic model, the influence of the wave hydrodynamic loads over the catenary mooring system of the DeepCWind and the OC3 Hywind platforms is assessed by comparing simulations for different sea states with and without the wave forces. The results show a variation in the tensions of the fairleads by an increment of the maximum, a decrement of the minimum and an increment of the standard deviation for the analyzed cases. The widening of the tension range of the line affects the fatigue resistance of the line by increasing $5 \%$ the damage in the most loaded line in a sever sea state.
\end{abstract}

\section{Introduction}

Floating Offshore Wind Turbine (FOWT) is one of the industrial sectors that will contribute to the reduction of the emissions of greenhouse gasses which drive global warming. FOWTs are a source green renewable energy that leverages the high and constant winds of the offshore sites due to the lack of obstacles. However, FOWT technology still needs research and development for a full deployment in a commercial stage [1].

Main efforts to reduce the uncertainties of the design of FOWT are focused on the improvement of the simulations tools [1]-[3]. These tools are based on the coupling of the numerical models of the different components that make up the FOWT such as the blade aerodynamics, the platform hydrodynamics, the mooring loads, and the overall structural response. IEA Tasks 23 and 30, also known as Offshore Code Comparison Collaboration Projects (OC3, OC4 and OC5) projects, are international projects with the aim of assessing the accuracy and reliability of these sophisticated tools and identifying research and development needs [4].

Within the different FOWT components, the mooring system design and its cost reduction are put in evidence [2]. Moreover, the "Secure, clean and efficient energy work program" of the UE Horizon2020 [5], specifies a reliable, sustainable and cost efficient mooring system of a scope for the floating wind technology. Also, Task 30 extension proposal (OC6) [6], identifies the importance on the investigation on wave forces on the mooring lines of the FOWTs.

The mooring system modelling approach can be treated as a quasi-static force by assessing the restoring forces from the static response of the mooring line, or as a fully dynamic system by a dynamic model such as the finite element 
method, the finite differences or the lumped mass model. These dynamic models assess the line behavior by solving the equations of motion of the mooring lines by taking into account the inertial forces, the internal forces by the extensional stiffness of the line, and the external forces as the wet weight, the seabed contact force and the hydrodynamic forces. From the point of view of the loads over the platform dynamics and its final design, the mooring dynamics are little important and have low effect on the overall behavior of the floating wind turbine. However, in mooring analysis design, the dynamics effects can be very important and can increase significantly the design tensions from the simulations [7], [8]. This difference, is stated on the safety factor of the mooring line design of the main standards such as DNV-GL[9], which is lower if a dynamic analysis is realized. Moreover, mooring dynamic models increase the degrees of freedom of the numerical problem and thus, the computational cost for FOWT analysis.

Within the dynamic analysis of the mooring lines, the main loads are the inertial effects, the hydrodynamics and gravity. The inertial effects are described by the acceleration of the line mass as well as the hydrodynamic added mass term, which accounts for the water scatter pressure from the acceleration of a body inside a fluid. The hydrodynamic forces are the drag term, which is assessed by the relative velocity between the water and the submerged body, and the inertia wave force term. The hydrodynamic forces are based on the variation of the Morison equation for cylindrical slender elements in motion. DNV-GL[9] recommends to apply the hydrodynamic effects over the mooring lines, except hydrodynamic wave forces. Then, only the mooring line dynamics are considered, as the line moves inside a still water.

This paper aims to highlight the influence of the wave hydrodynamic forces over catenary mooring lines for FOWTs. This influence is stated through the paper by the simulation and comparison of the results considering and disregarding the waves forces on the mooring lines. The selected examples for the simulations are: (1) an experiment performed on a cylindrical platform attached to a catenary line, (2) a simulation of the DeepCWind platform and (3) simulations of the OC3-Hywind platform. The influence of the wave hydrodynamics is analysed in terms of the variation of the tension in the mooring line at the fairlead, in terms of the motion of the platforms and in the loads on the tower base.

The simulations of the experiment of a cylindrical platform connected to a longitudinal catenary mooring line subjected to a regular wave train show a non-despicable tension increment at the fairleads due to the wave loads over the mooring lines. The experiment is compared with and without the hydrodynamic forces of the waves over the mooring lines. An increment of $6 \%$ of the tension at the fairlead is obtained if the wave loads are applied on the line. In addition, parametric studies are performed to assess the influence of varying the ratio between the horizontal and the vertical span of the mooring and of varying the diameter and weight of the mooring line.

In order to assess the effects of the wave forces over the catenary mooring system of a FOWT, two different platforms are studied under severe and normal sea states. The FOWTs studied are the well-known DeepCWind semisubmersible platform within the OC5 project characteristics [10] from the Marin experiments [11], and OC3 Hywind Spar platform[12]. Both platforms are simulated with and without adding the wave hydrodynamic force on the mooring lines for comparison purpose. The DeepCWind platform is simulated under the LC3.4 of the OC5 project with the severe sea state and without wind. The simulation results are compared with the test data and state the contribution of the increment of tension to the lines due to the wave's force. The OC3 Hywind platform is studied in a parametric study in order to assess the importance of the depth of the fairlead position, as in deep seas, wave loads decrease exponentially. The parametric study is performed by applying four different fairlead depths, equidistantly from the actual theoretical position up to the mean sea level. The OC3 Hywind is simulated under a normal and a severe sea states, with a dynamic wind in power production state.

The article is structured as follows. First, the FloaWDyn, the aero-hydro-servo-elastic model developed at UPC Barcelona-Tech used for the FOWT simulation is presented emphasizing the mooring model and the computation of the wave hydrodynamic forces on the mooring lines. Second, an experimental test is used to validate the model and assess the contribution of the wave loads on the mooring lines. Third, the simulations models and results of the 
DeepCWind and OC3 Hywind Spar are presented. Finally, the conclusions are presented and summarize the results obtained from the simulations and expose the influence of the wave loads on the mooring lines.

\section{FloaWDyn Model}

The FloaWDyn model is an aero-hydro-servo-elastic tool developed at UPC Barcelona-Tech. The FloaWDyn is based on a co-rotational Finite Element Model (FEM), able to decouple the overall dynamics of the whole platform from its deformations at each time step [13], [14].

\section{$2.1 \quad$ FEM co-rotational model}

FloaWDyn FEM model allows the use of bar elements such as trusses, beams based on Euler-Beam theory and triangular shell elements [13]. A general element independent co-rotational formulation is used [15], which in conjunction with the dynamic equilibrium equation, allows to obtain the nodal displacements field. This formulation deals with the dynamics of floating structures by allowing large rigid body motions but small strains. In general, each element places at its centroid one triad and others on the nodes defined, see Figure 1 . This technique allows to separate the element rigid motions from its internal deformations produced by the loads acting (inertial, internal and external loads). Once the internal deformations field is computed, the internal stresses can be finally computed.

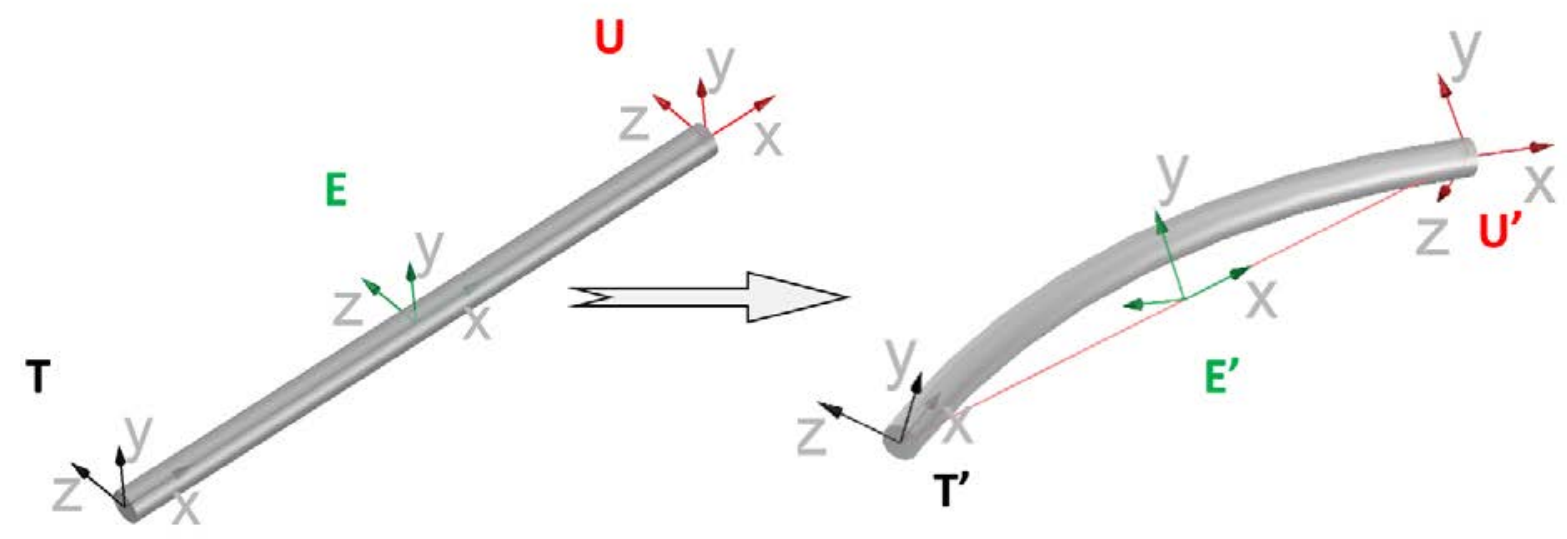

Figure 1: 3D Co-rotational frame for bar elements. Undeformed (left) and deformed element (right) [13]

\subsubsection{Dynamic analysis}

The equations of motion of the global system are obtained by applying the Newton's second law. Thus, by applying the Alembert's principle, the external, the internal and the inertial forces have to be in equilibrium at each time step.

The equations of motion are solved at each time step, by an iterative approach that updates the geometry and the internal forces. The solution of the system of equations yields to the increment of displacements between time steps in global coordinates.

For the time integration of the equations of motion, the Hilber-Hughes-Taylor (HHT) scheme [16] is adopted. 


\subsection{Aerodynamics}

The aerodynamics are assessed by the FAST AeroDyn model[17]. FAST AeroDyn is a Blade Element Momentum model which computes the aerodynamics of the rotor blades of a wind turbine. FAST AeroDyn is coupled with FloaWDyn in its standalone version. The aerodynamics consider temporal turbulence, but spatial turbulence is neglected. The wind speed is considered constant from the hub height which varies at each time step. Nevertheless, vertical wind velocity variation is considered by applying shear exponential law. Moreover, pitch and torque control models are based on FAST servo models, and the drive train is modelled as a rigid shaft.

The wind turbine forces over the yaw bearing are taken from Fast Aerodyn output results, which are updated at each time step in the tower coordinates system by accounting for the rotor azimuth, blade pitch and yaw position. Although spatial turbulence is not applied, the coupling of FAST AeroDyn allows an assessment of the main aerodynamic effects such as the tower shadow, tip and hub losses and the power produced by the turbine.

\subsection{Hydrostatic and Hydrodynamic Forces}

The hydrostatic forces occurring at the beam elements are computed from the buoyancy force of the submerged fraction of the element halved at each node. Thus, the hydrostatic force is split along the buoy ensuring the resultant buoyancy force will be virtually applied at the center of buoyancy. The hydrostatic forces over the shell elements are computed by the hydrostatic pressure acting at each centroid perpendicular to the shell plane. The pressure $p$ is assessed by the hydrostatic law as $p=-\rho_{w}|\boldsymbol{g}| \boldsymbol{r}_{\boldsymbol{z}} \cdot \boldsymbol{n}$, where $\rho_{w}$ is the water density, $\mathbf{g}$ is the gravity vector, $\boldsymbol{r}$ is the vector position of the centroid of the shell element, the subscript defines the coordinate Degree Of Freedom (DOF), and $\boldsymbol{n}$ is the unitary normal vector of the shell element pointing to the water.

The kinematic and dynamic properties of the waves are assessed by either regular or irregular formulations. Regular wave hydrodynamics can be computed by Airy linear theory or by high order theories such as Stokes $5^{\text {th }}$ order. Irregular wave kinematics are based on regular Airy linear wave theory and its components are assessed by the FFT and IFFT properties. Irregular wave trains can be defined from Jonswap spectrum or from an input wave profile.

The hydrodynamics of the beam elements are computed using the Morison equation for transversal forces. Moreover, the dynamic pressure is applied at the nodes in the axial beam direction of each element to assess the axial resultant force due to the dynamic wave pressure variation. At the free end points and cross section changing points an axial added mass term is considered based on the half sphere volume. On the other hand, the hydrodynamic forces over the shell elements are computed by the superposition of first order wave loads of the Potential Flow solution assessed by the Boundary Element Method code, Nemoh [18]. The code solves the incident, diffraction and radiation waves problems for a given structure in the frequency domain for several wave directions. Using superposition of the linearization of the first order wave potential, the overall force of an irregular wave train and the radiation damping can be easily computed from the amplitude and phase of the wave and the convolution integral respectively. Herein, instead of the resultant forces, the pressure values are used and applied at each node of the shell elements of the submerged part of the structure.

\subsection{Mooring model}

The mooring numerical model is a finite element model based on the slender rod model [19], with the addition of the material stiffness, small strain assumption and material damping for both axial and bending deformations [20].

The rod is defined by the centerline position $\mathbf{r}(s, t)$ as a function of arc-length " $s$ " and the time " $t$ ", as is shown in Figure 2. The centerline position defines the shape of the line. At any point of the line the tangent vector of the curve $\mathbf{t}$, the normal vector $\mathbf{n}$, and the binormal vector $\mathbf{b}$ are defined in Eq. (1) as the unit vector of the derivative of the position of the centerline, the unitary vector of the tangent vector and the cross product of $\mathbf{t}$ and $\mathbf{n}$ respectively, where prime denotes the derivative respect to $\mathrm{s}$. 


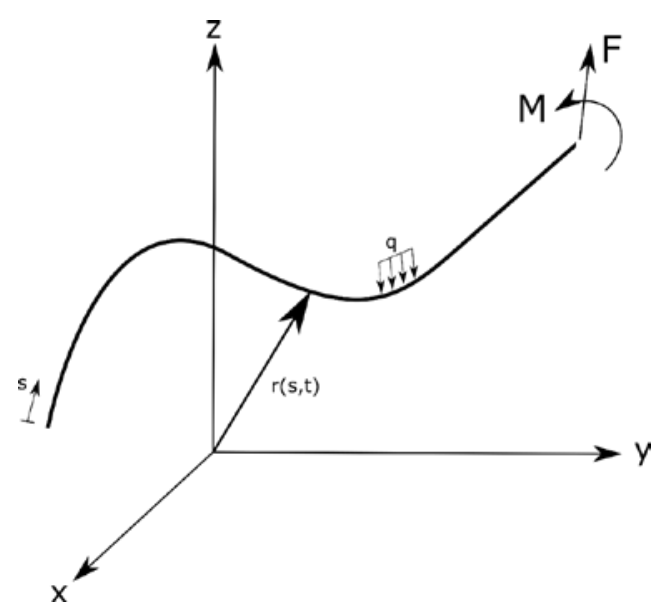

Figure 2: rod centerline sketch

$$
\boldsymbol{t}=\frac{\partial \mathbf{r} / \partial s}{\|\partial \mathbf{r} / \partial s\|}=\frac{\mathbf{r}^{\prime}}{\|\mathbf{r} \prime\|} ; \mathbf{n}=\frac{1}{\kappa} \frac{d \mathbf{t}}{d s}=\frac{1}{\kappa} \frac{\mathbf{r} \prime \prime}{\|\mathbf{r} \prime\|} ; \mathbf{b}=\mathbf{t} \times \mathbf{n}
$$

Where:

$\left\|\mathbf{r}^{\prime}\right\|=(1+\varepsilon), \varepsilon$ is the strain, and $\kappa$ is the curvature and is defined as $\kappa=\frac{\left\|\mathbf{r}^{\prime \prime}\right\|}{\left\|\mathbf{r}^{\prime}\right\|}$.

Conservation of the linear and angular momenta of a differential cable element leads to the translational equation of motion Eq. (2) and to the static rotatory equation of motion Eq. (3) by neglecting the rotatory inertia and the shear deformation. $\mathbf{F}$ and $\mathbf{M}$ are the resultant force and moment respectively of the internal stress state at one point acting on the centerline, $\mathbf{q}$ and $\mathbf{m}$ are the external applied force and moment per unit length, $\rho_{m}$ is the line density, $A$ is the cross section of the line, and the superposed dot denotes the derivative with respect to time.

$$
\begin{aligned}
& \mathbf{F}^{\prime}+\mathbf{q}=\rho_{m} A \ddot{\mathbf{r}} \\
& \mathbf{M}^{\prime}+\frac{\mathbf{r}^{\prime}}{\|\mathbf{r} \prime\|} \times \mathbf{F}+\mathbf{m}=0
\end{aligned}
$$

The resultant moment for an elastic rod according to Euler-Bernoulli theory with equal principal stiffness, adding rheological damping material and disregarding the torsional component of the stress is expressed in Eq. (5), where $E$ is the Young modulus of the material, $I$ is the inertia of the cross section of the line, and $\eta$ is the viscosity of the material.

$$
\mathbf{M}=E I \kappa \mathbf{b}+\eta I \dot{\kappa} \mathbf{b}=\frac{\mathbf{r}^{\prime}}{\left\|\mathbf{r}^{\prime}\right\|} \times\left(\left(E I+\eta I \frac{\dot{\kappa}}{\kappa}\right) \frac{\mathbf{r}^{\prime \prime}}{\left\|\mathbf{r}^{\prime}\right\|}\right)=\frac{\mathbf{r}^{\prime}}{\|\mathbf{r} \prime\|} \times\left(E I \frac{\mathbf{r}^{\prime \prime}}{\|\mathbf{r} \prime\|}+\eta I\left(\frac{\mathbf{r}^{\prime \prime} \cdot \dot{\mathbf{r}}^{\prime \prime}}{\mathbf{r}^{\prime \prime} \cdot \mathbf{r}^{\prime \prime}}-\frac{\mathbf{r}^{\prime} \cdot \dot{\mathbf{r}}^{\prime}}{\mathbf{r}^{\prime} \cdot \mathbf{r}^{\prime}}\right) \frac{\mathbf{r}^{\prime \prime}}{\left\|\mathbf{r}^{\prime}\right\|}\right)
$$

By neglecting the applied linear moment per unit length $\mathbf{m}$, taking into account the constitutive equation of the rod by assuming a linear stretching from Eq. (5), and expressing the tension of the rod in terms of the elongation and the elongation velocity in Eq. (6), the governing equations can be described as Eq. (7):

$$
\begin{aligned}
& \boldsymbol{r}^{\prime} \cdot \boldsymbol{r}^{\prime}=(1+\varepsilon)^{2}=1+2 \varepsilon+O\left(\varepsilon^{2}\right) \\
& T=N=A E \varepsilon+\eta A \dot{\varepsilon} \\
& \left.\begin{array}{c}
\rho_{m} A \ddot{\mathbf{r}}+\left(E I \frac{\mathbf{r}^{\prime \prime}}{\left\|\mathbf{r}^{\prime}\right\|}+\eta_{B} I\left(\frac{\mathbf{r}^{\prime \prime} \cdot \dot{\mathbf{r}}^{\prime \prime}}{\mathbf{r}^{\prime \prime} \cdot \mathbf{r}^{\prime \prime}}-\frac{\mathbf{r}^{\prime} \cdot \dot{\mathbf{r}}^{\prime}}{\mathbf{r}^{\prime} \cdot \mathbf{r}^{\prime}}\right) \frac{\mathbf{r}^{\prime \prime}}{\left\|\mathbf{r}^{\prime}\right\|}\right)^{\prime \prime}-\left(\lambda \frac{\mathbf{r}^{\prime}}{\left\|\mathbf{r}^{\prime}\right\|}\right)^{\prime}=\mathbf{q} \\
\frac{1}{2}\left(\mathbf{r}^{\prime} \cdot \mathbf{r}^{\prime}-1\right)+\frac{\eta_{A}}{E}\left(\mathbf{r}^{\prime} \cdot \dot{\mathbf{r}}^{\prime}\right)-\left(\frac{E I}{E A}+\frac{\eta_{B} I}{E A}\left(\frac{\mathbf{r}^{\prime \prime} \cdot \dot{\mathbf{r}}^{\prime \prime}}{\mathbf{r}^{\prime \prime} \cdot \mathbf{r}^{\prime \prime}}-\frac{\mathbf{r}^{\prime} \cdot \dot{\mathbf{r}}^{\prime}}{\mathbf{r}^{\prime} \cdot \mathbf{r}^{\prime}}\right)\right) \kappa^{2}-\frac{\lambda}{E A}=0
\end{array}\right\}
\end{aligned}
$$


Where $\lambda$ is the Lagrange multiplier defined by the equation (9),

$$
\lambda=T-\left(E I+\eta I\left(\frac{\mathbf{r}^{\prime \prime} \cdot \dot{\mathbf{r}}^{\prime \prime}}{\mathbf{r}^{\prime \prime} \cdot \mathbf{r}^{\prime \prime}}-\frac{\mathbf{r}^{\prime} \cdot \dot{\mathbf{r}}^{\prime}}{\mathbf{r}^{\prime} \cdot \mathbf{r}^{\prime}}\right)\right) \kappa^{2}
$$

To take into account the hydrodynamic forces, the external force per unit length $\mathbf{q}$ is defined as:

$$
\mathbf{q}=\mathbf{f}_{h g}+\mathbf{f}_{a m}+\mathbf{f}_{D, t}+\mathbf{f}_{D, n}+\mathbf{f}_{s b}
$$

Where $\mathbf{f}_{h g}$ is the hydrostatic and gravity forces, $\mathbf{f}_{a m}$ is the hydrodynamic inertia force, $\mathbf{f}_{D, t}$ and $\mathbf{f}_{D, n}$ are respectively the hydrodynamic tangential and normal drag forces, and $\mathbf{f}_{s b}$ is the seabed contact force. These forces per unit length can be expressed as:

$$
\begin{aligned}
& \mathbf{f}_{h g}=\rho_{m} A \mathbf{g}-\rho_{w} A \mathbf{g}=\gamma_{w} \mathbf{e}_{z} \\
& \mathbf{f}_{a m}=-A \rho_{w} C_{a} \ddot{\mathbf{r}}^{n}+A \rho_{w} C_{m} \dot{\mathbf{V}}^{n} \\
& \mathbf{f}_{D, t}=\frac{1}{2} \rho_{w} C_{D, t} d\left|\mathbf{V}^{t}-\dot{\mathbf{r}}^{t}\right|\left(\mathbf{V}^{t}-\dot{\mathbf{r}}^{t}\right) \\
& \mathbf{f}_{D, n}=\frac{1}{2} \rho_{w} C_{D, n} d\left|\mathbf{V}^{n}-\dot{\mathbf{r}}^{n}\right|\left(\mathbf{V}^{n}-\dot{\mathbf{r}}^{n}\right) \\
& \mathbf{f}_{s b, z}=-G_{k} d\left(\mathbf{r}_{z}+\operatorname{depth}\right)-2 G_{c} \sqrt{\rho_{m} A G_{k} d} \min \left(\dot{\mathbf{r}}_{z} ; 0\right) \quad \text { if } \mathbf{r}_{z}+\text { depth }<0 \\
& \mathbf{f}_{s b, y}=-\rho_{m}|\mathbf{g}| \mathrm{G}_{\mu} \min \left(\frac{\dot{\mathbf{r}}_{x y}}{G_{v c}} ; 1\right)
\end{aligned}
$$

The hydrodynamic forces $\mathbf{f}_{a m}, \mathbf{f}_{D, n}, \mathbf{f}_{D, t}$ are based on the Morison's equation for oscillating cylinders [21]. The seabed effect is set as a normal force on the flat seabed based on a spring-damper system. The damping force only appears when the node on the seabed penetrates to the soil (negative velocity) and is disregarded when the node moves in opposite direction. In the equation (10) the superscript $n$ and $t$ refer to the normal or the tangent component of the line respectively; $\mathbf{g}$ is the gravity vector, the $\gamma_{w}$ is the wet weight per meter length; the $\mathbf{V}$ is the water particle velocity; the $\dot{\mathbf{V}}$ is the water particle acceleration; the $G_{K}$ is the ballast seabed coefficient or the seabed stiffness in $\left[N / \mathrm{m}^{3}\right]$; the depth is the sea depth; the $G_{C}$ is the fraction of critical damping of ground, $G_{\mu}$ is the friction coefficient and $G_{v c}$ is the cut-off velocity of friction. The hydrodynamic coefficients are: $C_{D}$ the drag coefficient, $C_{a}$ the added mass coefficient and $C_{m}$ the inertia coefficient.

\section{Experimental validation test on wave hydrodynamic influence}

In order to assess the importance of the wave hydrodynamics over the mooring lines, a comparison between experimental test and the simulations with and without the wave hydrodynamics on the lines is performed. In addition, the simulation is used for the validation of the model.

The experiment was presented by Paredes et. al [22] and its setup consists in a cylindrical floater attached to one mooring line facing the wave generator and a spring attached at the other side. The experiment measures the motions of the floater excited by a regular wave train and the tension of the mooring line. The Figure 3 shows a sketch of the test and its main dimensions.

The buoy is defined by 560 elements to solve the Potential Flow hydrodynamics. In the dynamic analysis the buoy is treated as a rigid body, then there are $6 \mathrm{DOF}$, three for the translations and three for the rotations. The mooring line is defined by 25 elements and 26 nodes.

The regular wave train generated has a height of 0.1 meters and a period of $1.4 \mathrm{~s}$. The main parameters of the floating platform, the mooring line and the spring are presented in Table 1 from [22]. It is assumed that the scale of the experiment is $1 / 100$, thus a regular wave of $10 \mathrm{~m}$ height and $14 \mathrm{~s}$ period, with a depth of about $100 \mathrm{~m}$ and a longitudinal span of the mooring line of $559 \mathrm{~m}$ are considered. 


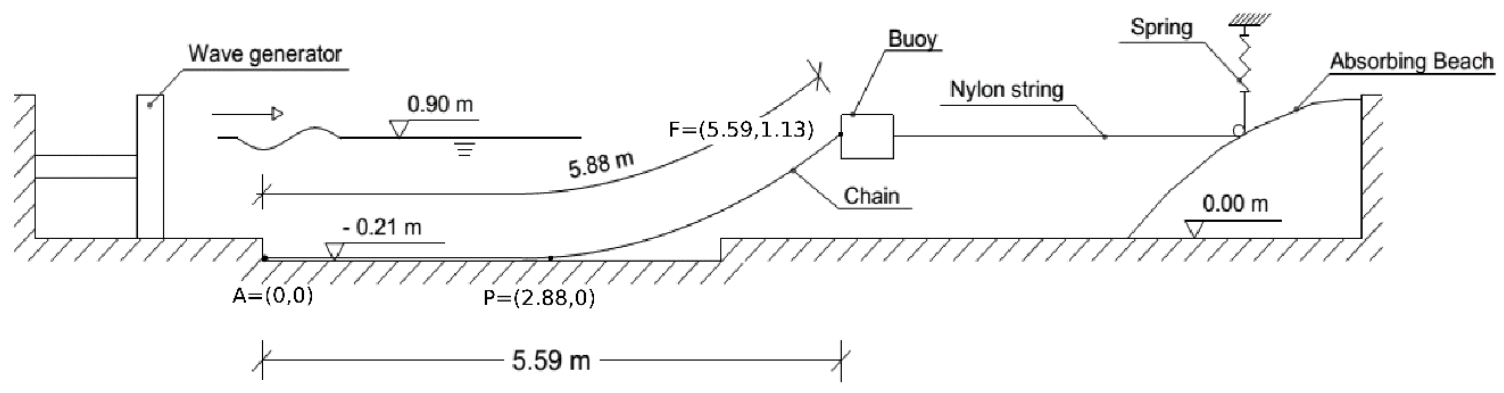

Figure 3: Sketch of the experimental setup developed by Paredes [22].

Table 1: Experimental data extracted from [22]

\begin{tabular}{|l|l|l|l|}
\hline WAVE TANK & & MOORING LINES & \\
\hline Scale & $1: 1$ & Horizontal span [m] & 5.59 \\
\hline Depth $[\mathrm{m}]$ & 1.11 & Length $[\mathrm{m}]$ & 5.88 \\
\hline TESTS & & Apparent Diameter [mm] & 2.7 \\
\hline $\mathrm{H}[\mathrm{m}]$ & 0.1 & $\begin{array}{l}\text { Submerged weight per unit } \\
\text { length [N/m] }\end{array}$ & 0.382 \\
\hline $\mathrm{T}[\mathrm{s}]$ & 1.4 & $\begin{array}{l}\text { Dry weight per unit length } \\
\text { [N/m] }\end{array}$ & 0.436 \\
\hline FLOATER & & Axial Stiffness (EA) [N] & 10000 \\
\hline Diameter [m] & 0.5 & Cdt & 0.5 \\
\hline Height [m] & 0.4 & Cdn & 2.5 \\
\hline CM [m] (from centre of floatation) & -0.072 & Ca & 0.4129 \\
\hline Draft [m] & 0.18 & SPRING & \\
\hline Mass $[\mathrm{kg}]$ & 35.28 & $\mathrm{~K}[\mathrm{~N} / \mathrm{m}]$ & 5.36 \\
\hline $\begin{array}{l}\text { Inertia }\left[\mathrm{kg} \cdot \mathrm{m}^{2}\right] \text { (around centre of } \\
\text { buoyancy) }\end{array}$ & 0.852 & $\mathrm{X}_{0}[\mathrm{~m}]$ & 1.3 \\
\cline { 3 - 4 } & & $\mathrm{T}_{0}[\mathrm{~N}]$ & 1.3 \\
\hline
\end{tabular}

The results in Figure 4 show good agreement between the simulations and the experimental data. The heave and the pitch motion of the buoy are the best fitted results. For the surge motion, the experimental data shows a larger mean offset than the simulations, as a possible consecuence of the mean drift force due to second order wave force. Nevertheless, the tension of the fairlead is well captured. The experimental data show a larger mooring line peak tension. Also, the trough region is deeper for the experimental data. Results including wave hydrodynamics on the moorings better adjust to the experimental peak tension at the fairlead.

The platform dynamics are slightly influenced by the wave loads on the mooring lines. Very low varitions can be observed in surge, heave and pitch motions due to the inclusion of the wave forces on mooring lines. However, noticeable differences appear in the tension force at the fairlead as is shown in Figure 5 if waves forces on mooring line are considered or not. If wave forces are considered, the trough of the tension is wider causing the tension to increase substantially. Moreover, the maximum peak tension at the fairlead increases of $6 \%$. This results show the importance to inquire at the effect of wave hyrodynamics over the mooring lines. In the experimental setup, the mooring line presents a ratio about 2.5 between the horizontal projection of the suspended length and the fairlead depth as shown in Figure 3. Moreover, mooring lines can also present larger ratios between the suspended horizontal and vertical span and, thus, wave hydrodynamics could have a more significant influence because the most energetic wave hydrodynamics are located near the wave surface. 

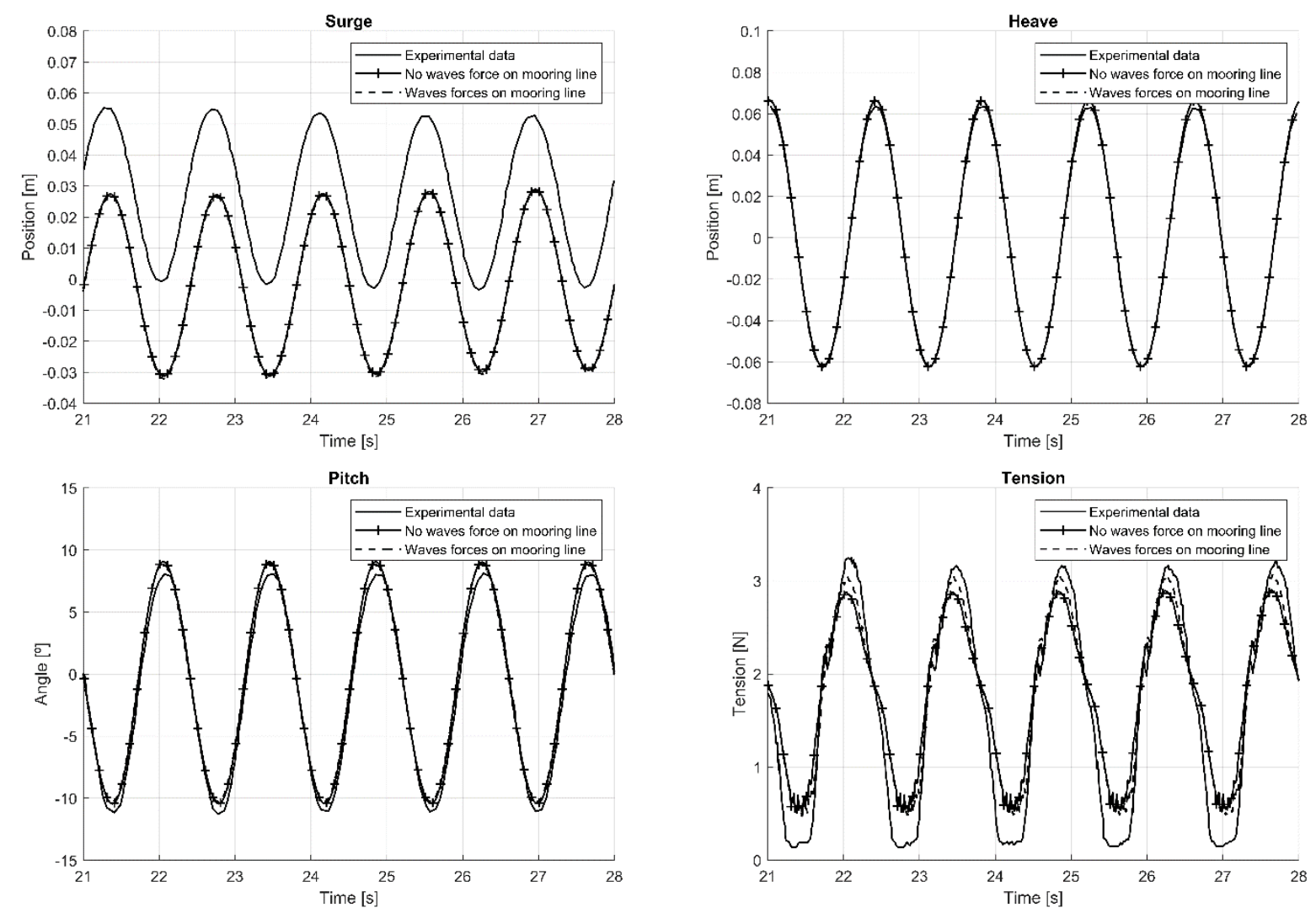

Figure 4: Experimental data and simulation results $(T=1.4 \mathrm{~s}, \mathrm{H}=0.100 \mathrm{~m})$

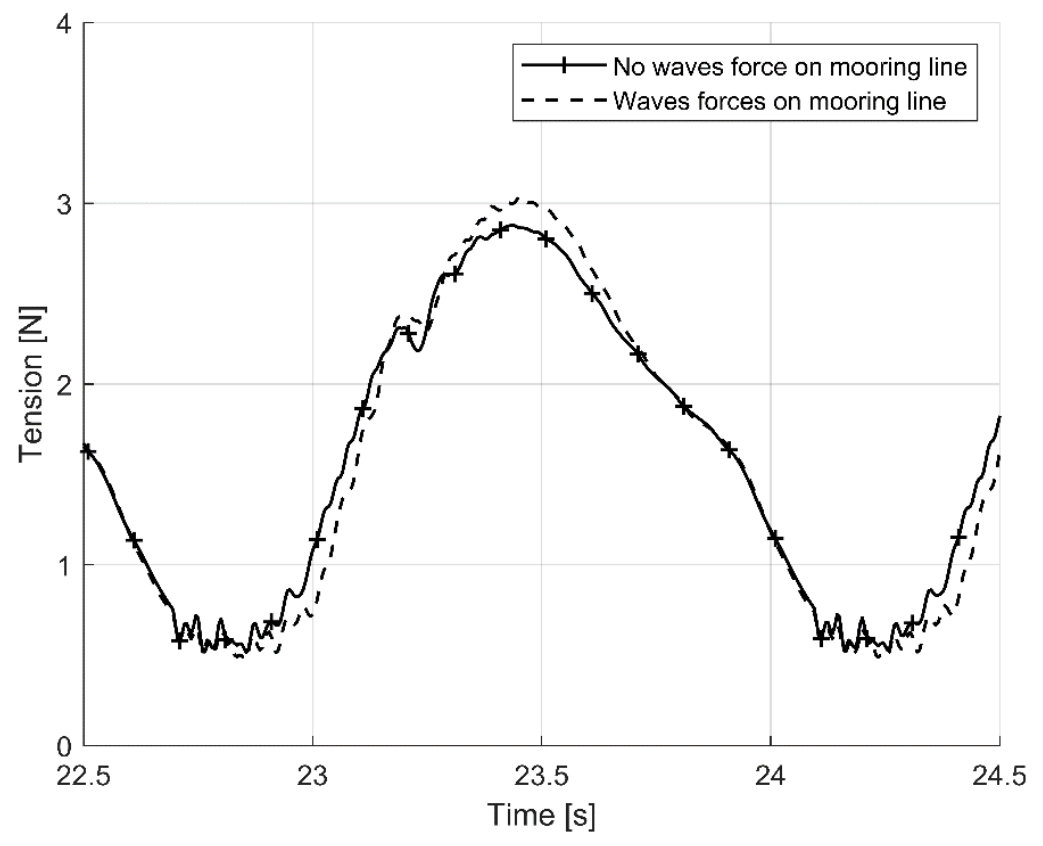

Figure 5: Tension of the numerical simulations ( $T=1.4 \mathrm{~s}, H=0.100 \mathrm{~m})$ 


\subsection{Horizontal and vertical span ratio evaluation}

As the wave hydrodinamics decreases with the depth, exponentially for deep waters, the effects of the hydrodynamics may be more noticeable for more flaten configurations. A comparison study between three different ratios between the horizontal span of the suspended length and the fairlead vertical distance is performed in order to assess the contribuction of the hydrodynamics over the line. The comparison is performed assuming the same regular wave train, platform and line characteristics, but varying the total length and the anchor point position. A sketch of the initial configuration of the three studied scenarios with horizontal and vertical span of the suspended line ratios of 1.65, 2.65 and 3.65 is shown in Figure 6. Also the initial restoring force of the spring is modified to match the inital horizontal restoring force of the line, as the longer the suspended length the larger the tension in the mooring line.

Figure 7 shows the comparison of one cycle tension of the simulations. The main difference between the simulations is the increase of the mean tension as was expected due to the longer suspended line segment. The increase of the mean tension also implies a reduction of slackness of the line during the simulation reducing internal vibrations as can be seen in the troughs of all the three simulations. Table 2 shows the comparison of the maximum, minimum, mean and range tensions at the fairlead of the simulations. The results show an important decrease of the minum tension of the line for the ratio $\mathrm{H} / \mathrm{V}$ of 3.65 when including wave hydrodynamics on the line. The minium tensions for the $\mathrm{H} / \mathrm{V}$ ratios of 1.65 and 2.65 have lower variations because they are determined by a slack event. The maximum tension increases in all three scenarios, with a maximum increment of about $0.15 \mathrm{~N}$ for the 2.65 scenario. The other two scenarios have a similar absoulte increase of about 0.09-0.1 N. To summarize, the ranges between the minum and maximum tension for the simulations have an increase between a 5.1 and $6.4 \%$ if wave hydrodynamics over the mooring lines are accounted for.

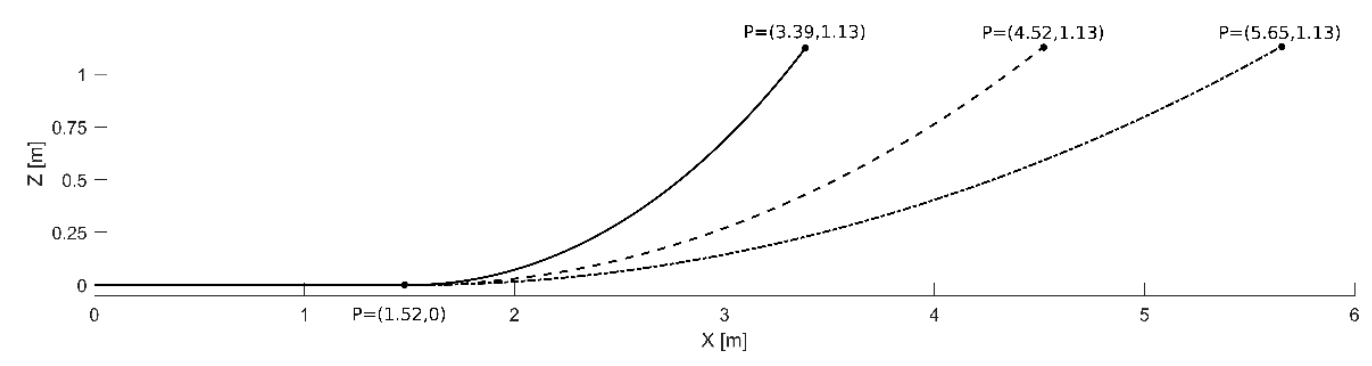

Figure 6: Sketch of mooring line shape of the H/V parametric study

\subsection{Chain diameter parametric study}

The wave hydrodynamics, drag and wave inertial forces, also depend on the diameter of the chain. Moreover, the variation of the chain diameter also affects on the mean tension of the line due to the variation of the wet weight. Then, the influence of the hydrodynamic forces on the mooring line may vary depending on the line diameter.

To assess the influence of the line diameter on the wave hydrodynamic forces on the mooring line, the experiment presented in Section 3, named as case 0 (C0), is repeated by decreasing and increasing the chain diameter for case 1 (C1) and case 2(C2), respectively. The parameters that differ in these three cases are the diameter, the wet weight and the dry weight, as shown in Table 3. The Figure 8 shows the tension cycle for the $\mathrm{C} 1$ and $\mathrm{C} 2$ simulations, whereas CO result is shown in Figure 5. 


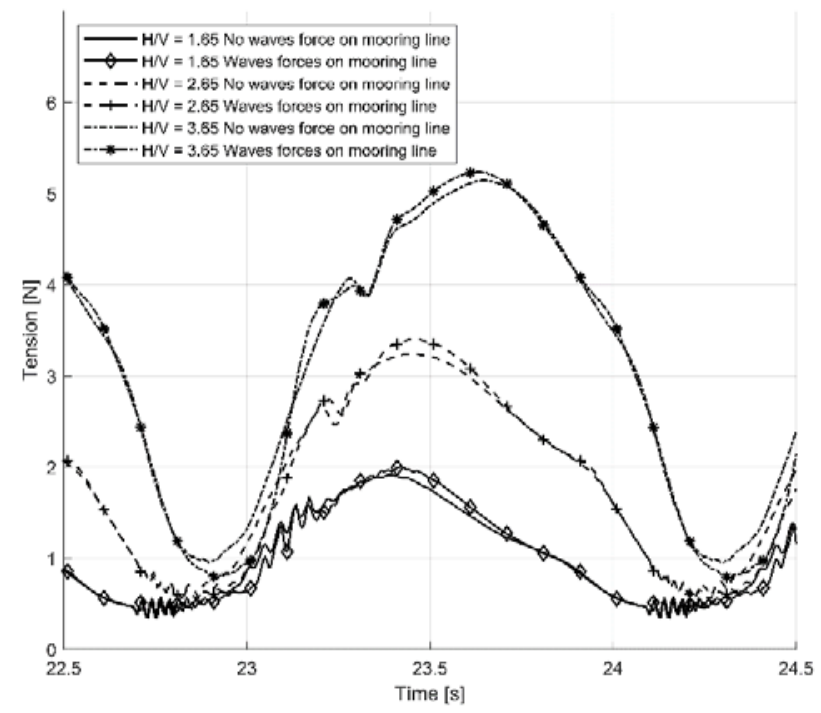

Figure 7: Tension of $H / V$ parametric study $(T=1.4 \mathrm{~s}, H=0.100 \mathrm{~m})$

Table 2: Tension comparison for the $H / V$ parametric study ( $T=1.4 \mathrm{~s}, H=0.100 \mathrm{~m}$ )

\begin{tabular}{|c|c|c|c|c|c|c|c|c|c|c|}
\hline & & $\begin{array}{l}\min \\
{[N]}\end{array}$ & $\begin{array}{c}\Delta \min \\
{[N]}\end{array}$ & $\begin{array}{c}\Delta \min \\
(\%)\end{array}$ & $\begin{array}{c}\max \\
{[N]}\end{array}$ & $\begin{array}{c}\Delta \max \\
{[N]}\end{array}$ & $\begin{array}{c}\Delta \max \\
(\%)\end{array}$ & $\begin{array}{c}\max -\min \\
{[N]}\end{array}$ & $\begin{array}{l}\Delta(\max \\
-\min )[N]\end{array}$ & $\begin{array}{l}\Delta(\max \\
-\min )(\%)\end{array}$ \\
\hline \multirow{2}{*}{$H / V=1.65$} & $\begin{array}{l}\text { No wave } \\
\text { Hydrodynamics }\end{array}$ & 0.345 & & & 1.907 & & & 1.562 & & \\
\hline & $\begin{array}{l}\text { Wave } \\
\text { Hydrodynamics }\end{array}$ & 0.352 & 0.007 & $1.9 \%$ & 1.993 & 0.086 & $4.5 \%$ & 1.641 & 0.079 & $5.1 \%$ \\
\hline \multirow{2}{*}{$H / V=2.65$} & $\begin{array}{l}\text { No wave } \\
\text { Hydrodynamics }\end{array}$ & 0.558 & & & 3.263 & & & 2.704 & & \\
\hline & $\begin{array}{l}\text { Wave } \\
\text { Hydrodynamics }\end{array}$ & 0.550 & -0.008 & $-1.4 \%$ & 3.415 & 0.152 & $4.7 \%$ & 2.865 & 0.160 & $5.9 \%$ \\
\hline \multirow{2}{*}{$H / V=3.65$} & $\begin{array}{l}\text { No wave } \\
\text { Hydrodynamics }\end{array}$ & 0.959 & & & 5.142 & & & 4.184 & & \\
\hline & $\begin{array}{l}\text { Wave } \\
\text { Hydrodynamics }\end{array}$ & 0.787 & -0.172 & $-17.9 \%$ & 5.239 & 0.097 & $1.9 \%$ & 4.453 & 0.269 & $6.4 \%$ \\
\hline
\end{tabular}

The Table 4 shows the summary of the results of the simulation for comparison purpose. The simulations show larger increments for the maximum tension in larger diameters (C2), but these are relatively smaller than in the small diameter (C1), due to the increase in the mean tension. For the minimum tension, the C1 presents larger tension, whereas for the other cases the minimum tension decreases with the increase of the diameter. Finally, the tension amplitude presents larger increments for larger diameters (C2).

Table 3: Chain characteristics for the diameter parametric study

\begin{tabular}{|l|l|l|l|}
\hline Parameter & C0 & C1 & C2 \\
\hline Apparent diameter $[\mathrm{mm}]$ & 2.7 & 1.9 & 3.2 \\
\hline Submerged weight per unit length $[\mathrm{N} / \mathrm{m}]$ & 0.382 & 0.188 & 0.542 \\
\hline Dry weight per unit length $[\mathrm{N} / \mathrm{m}]$ & 0.436 & 0.215 & 0.618 \\
\hline
\end{tabular}



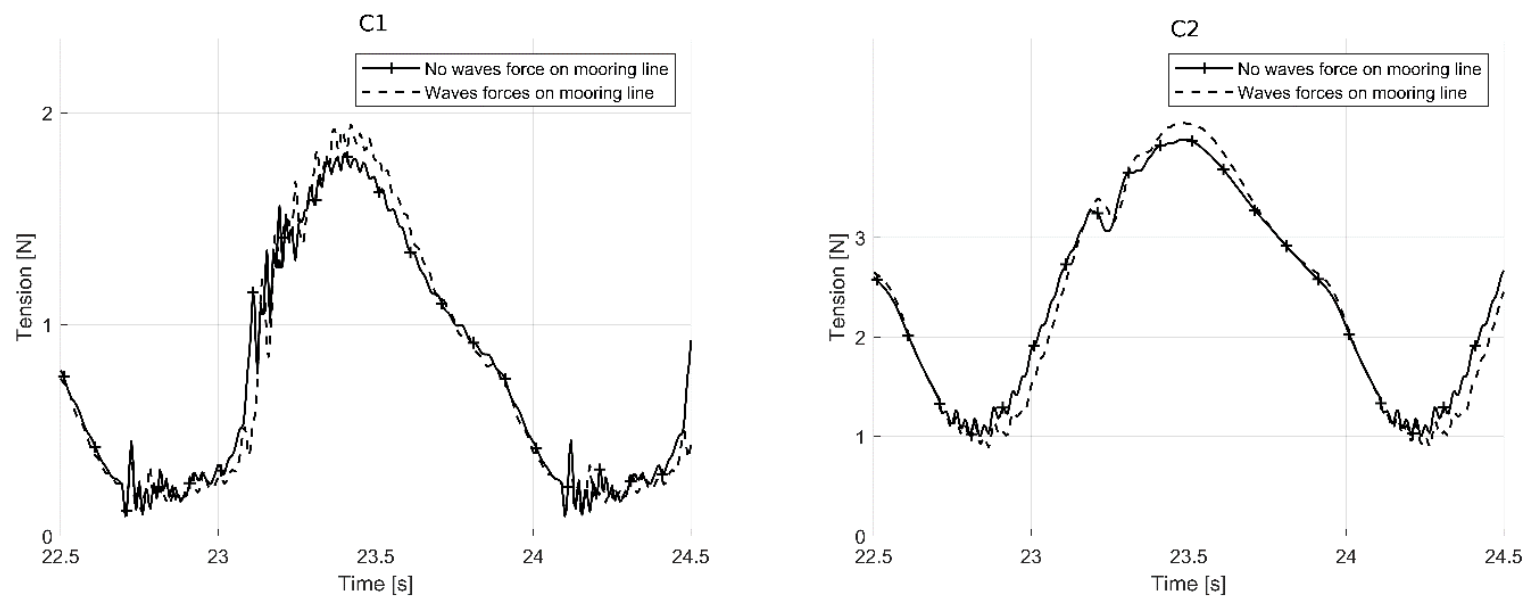

Figure 8: Tension cycle for C1 (left) and C2 (right) simulations

Table 4: Tension comparison for the diameter parametric study.

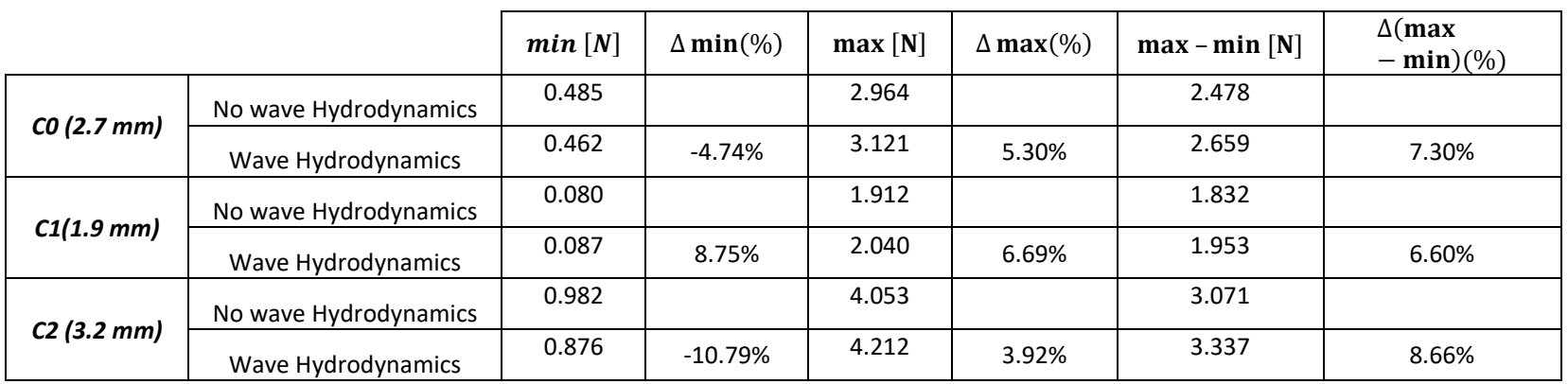

\section{$4 \quad$ FOWT analysis including wave hydrodynamics over moorings}

FOWT mooring systems can also be subjected to an increment of the tension and tension range due to wave hydrodynamics. In order to assess the contribution of the hydrodynamic wave loads over the mooring lines, two referent floating platforms are studied by analyzing its behavior in a different sea states. These referent platforms are the DeepCWind and the OC3 Hywind platform. The DeepCWind is a semisub platform [23] which was analyzed during the OC5 project [10] and the results were compared with the available experimental data. This platform presents a draft of $20 \mathrm{~m}$ and the fairleads are located at $14 \mathrm{~m}$ depth. In this paper, the inclusion of wave hydrodynamics on the moorings will be compared with the available experiments. The OC3 Hywind [12] is a steel spar platform with a $120 \mathrm{~m}$ draft and the fairleads located at $70 \mathrm{~m}$ depth. Moreover, a parametric study is performed by adding three extra simulations using the same mooring system but placing the fairleads at 3 different heights above the initial one. The shift of the fairleads allows a comparison of the influence of the depth for the wave hydrodynamics on the mooring lines.

The sea state used in the simulations for both platforms is the design sea state of the OC5 Phase II project with a significant wave height ( $\mathrm{Hs}$ ) of $10.5 \mathrm{~m}$ and a peak period (Tp) of 14.3s. Moreover, an operational sea state with a $\mathrm{Hs}$ of $7.1 \mathrm{~m}$ and a Tp of $12.1 \mathrm{~s}$ is used for the OC3 Hywind platform to assess the different contribution of the wave loads on the mooring line for different sea states.

DeepCWind 
The OC5 phase II project is based on the scale model of the DeepCWind semisubmersible concept [23]. The floating platform is composed by 4 steel vertical pontoons connected by trusses, from where the tower is connected, see Figure 9 left. The 1/50 scale model test of the concept was experimentally tested at the MARIN offshore basin [11] with a specifically built scaled wind turbine for the wave tank [24],[25], Figure 9 right.

The simulation performed is the load case LC3.4 of the OC5 Phase II project [8] where the platform is tested under the design wave state without wind (see Table 5 for more details). The load case lasts $3 \mathrm{~h}$ to ensure a full development of the irregular wave train, which was provided by the project [10]. The simulation results with and without wave hydrodynamics are also compared with the experimental data.

Table 5: Description of the LC 3.4 of the OC5 Task II project [8]

\begin{tabular}{|c|c|c|c|c|c|c|}
\hline Load Case & Description & RPM & $\begin{array}{c}\text { Blade Pitch } \\
\text { (deg) }\end{array}$ & Wave Condition & $\begin{array}{c}\text { Wind } \\
\text { Condition }\end{array}$ & $\begin{array}{c}\text { Sim. Length } \\
\text { (min) }\end{array}$ \\
\hline 3.4 & Design Wave & 0 & 90 & $\begin{array}{c}\text { Irregular: } H_{s}=10.5 \mathrm{~m}, \\
T_{p}=14.3 \mathrm{~s}, \gamma=3.0, \\
\text { JONSWAP }\end{array}$ & N/A & 180 \\
\hline
\end{tabular}

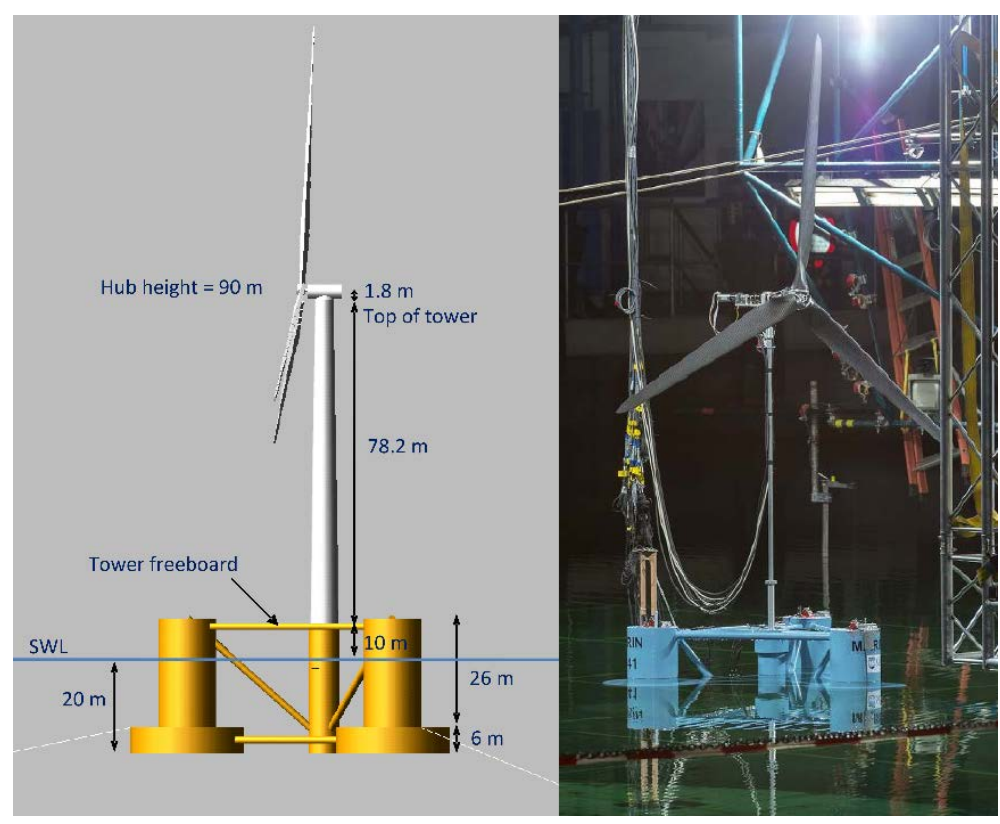

Figure 9: DeepCWind concept [23] (left); OC5 task II Scale model [11] (right) 


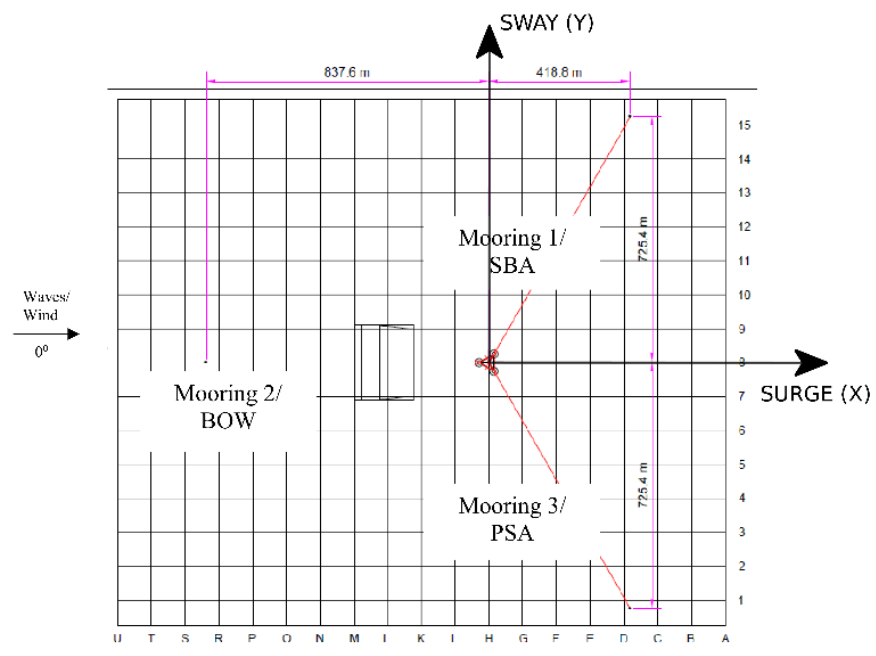

Figure 10: Full-scale equivalent mooring system setup [11]

\subsubsection{DeepCWind FloaWDyn Model}

The DeepCWind model used for the simulations is the model set up at UPC for the OC5 Phase II project [14]. The platform plus the tower is modeled using 412 beam elements with 401 nodes. The pontoons and tower are discretized in $1 \mathrm{~m}$ length elements, and the braces in $2 \mathrm{~m}$ length elements. The mooring system is discretized in 75 elements, with 25 elements per line, and a total number of 78 nodes.

\section{Structural properties}

The FEM beam model was adjusted, by adding the required ballast mass and adding lumped masses and inertias to specific nodes, to get main physical properties of the tested model, converted to full scale values, presented in Table 6.

Table 6: DeepCWind Test Model Physical properties [10]

\begin{tabular}{|l|l|}
\hline Mass [kg] & $1.3958 \mathrm{E}+7$ \\
\hline Draft [m] & 20 \\
\hline Displacement $\left[\mathrm{m}^{3}\right]$ & $1.3917 \mathrm{E}+4$ \\
\hline CM below SWL $[\mathrm{m}]$ & 8.07 \\
\hline Roll inertia in $\mathbf{C M}\left[\mathrm{kg} \cdot \mathrm{m}^{\mathbf{2}}\right]$ & $1.3947 \mathrm{E}+10$ \\
\hline Pitch inertia in $\mathbf{C M}\left[\mathrm{kg} \cdot \mathrm{m}^{\mathbf{2}}\right]$ & $1.5552 \mathrm{E}+10$ \\
\hline Yaw inertia in $\mathrm{CM}\left[\mathrm{kg} \cdot \mathrm{m}^{\mathbf{2}}\right]$ & $1.3692 \mathrm{E}+10$ \\
\hline
\end{tabular}

\section{Hydrodynamic Properties}

The hydrodynamic calibration of the model is set from the experimental free decay and regular wave tests [14]. Since the hydrodynamics in the FloaWDyn code when using beam elements are based on the Morison's equation, the hydrodynamic coefficients to calibrate are the drag coefficients $\left(C_{d}\right)$ and the inertia coefficients $\left(C_{m}\right)$ for each structural element. Also, each element added mass coefficient $\left(C_{a}\right)$ are adjusted to match with the total system added mass. The values used for the simulation are presented in Table 7. 
Table 7: FloaWDyn DeepCWind Hydrodynamic coefficients [14]

\begin{tabular}{|l|l|l|l|l|l|l|}
\cline { 2 - 8 } \multicolumn{1}{c|}{} & \multicolumn{2}{l|}{$\mathrm{C}_{\mathrm{d}}$} & \multicolumn{2}{l|}{$\mathrm{C}_{\mathrm{a}}$} & \multicolumn{2}{l|}{$\mathrm{C}_{\mathrm{m}}$} \\
\cline { 2 - 8 } \multicolumn{1}{l|}{} & Trans & Long. & Trans & Long. & Trans & Long. \\
\hline Upper Columns & 0.600 & -- & 0.52 & -- & 1.5 & -- \\
\hline Lower Columns & 0.600 & 1.60 & 0.52 & 0.67 & 1.5 & 0.65 \\
\hline Tower Columns & 0.663 & 0.80 & 0.51 & 0.88 & 1.5 & 0.87 \\
\hline Cross-brace members & 0.564 & -- & 0.50 & -- & 1.5 & -- \\
\hline Mooring elements & 1.880 & 0.86 & 0.50 & -- & 1.5 & -- \\
\hline
\end{tabular}

\section{Mooring properties}

The characteristics of the mooring lines are described in Table 8. The three mooring lines are considered identical, instead of using different values for each line, by averaging the characteristics of the three lines. The hydrodynamic terms used are the tangential and normal drag coefficients $\left(C_{d t}, C_{d n}\right)$, the added mass term $\left(C_{a}\right)$ and the inertia term $C_{m}=1+C_{a}$, which are set after a calibration of the model during OC5 Taskll [8], [14]. The axial damping ratio $\left(\xi_{A}\right)$ is set to $3 \%$. The real scale equivalent mooring system setup for the experimental campaign is shown in Figure 10.

Table 8: Characteristics of DeepCWind mooring lines [10]

\begin{tabular}{|l|l|}
\hline Number of mooring lines & 3 \\
\hline Angle between adjacent lines & $120 \circ$ \\
\hline Radius to anchors from centerline [m] & 837.6 \\
\hline Radius to fairleads from centerline [m] & 40.868 \\
\hline Unstretched mooring line length [m] & 835.5 \\
\hline Volume-equivalent diameter [m] & 0.1393 \\
\hline Mooring line mass density [kg/m] & 125.6 \\
\hline Equiv. line extensional stiffness [N] & $7.49 \mathrm{E}+8$ \\
\hline Cdt & 0.86 \\
\hline Cdn & 1.875 \\
\hline Ca & 0.5 \\
\hline $\boldsymbol{\xi}_{\boldsymbol{A}}$ & $3 \%$ \\
\hline
\end{tabular}

\subsubsection{Results}

The results of the simulations of the LC3.4 are compared with the experimental data, focusing on the most affected parameters result: the surge motion of the platform and the tension of the mooring lines.

The Figure 11 shows the PSD of the surge motion of the platform. The results show a lower response of the simulations for the lower frequency range, but good agreement in the wave frequency. This difference is probably due again to not considering second order wave theory in wave hydrodynamics. The simulation which includes wave hydrodynamics forces on mooring lines clearly shows a higher energy peak in the mooring frequency range than without waves forces. 

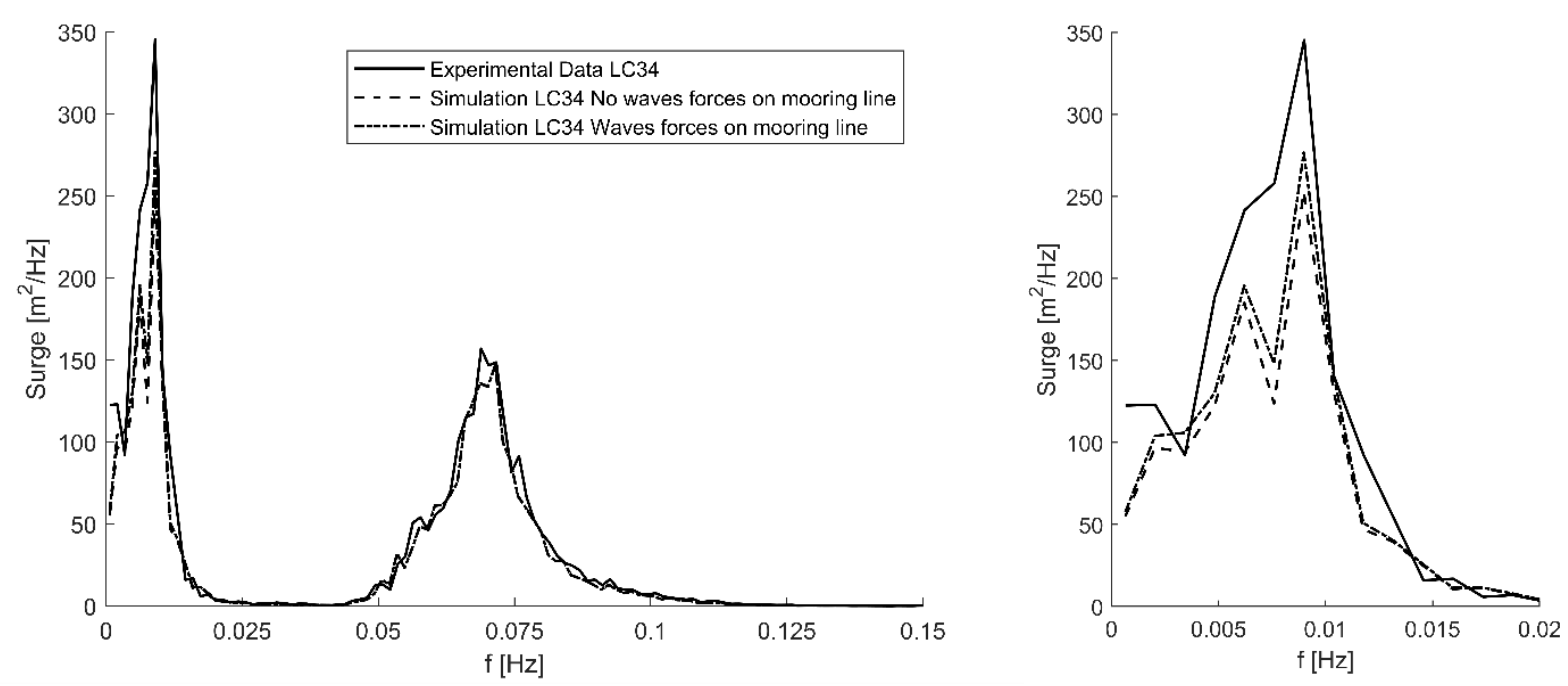

Figure 11: PSD of Surge motion of LC34

The tension at the fairleads also differ depending on if the hydrodynamics over the mooring lines are considered or not. The results show a reduction of the minimum tension, an increase of the maximum tension and an increase of the standard deviation (along the 10800s simulation) of the tension at the fairleads for lines 1 and 3 , the ones not aligned with the wave direction. These variations represent an increase of about $4.25 \%$ of the standard deviation and of about $1.45 \%$ of the maximum tension for lines 1 and 3 (Table 9). On the other hand, line 2 presents a larger minimum tension and a smaller maximum tension. Minimum tension events take place in the high nonlinear slacksnap phenomena. The maximum tension is only reduced by $-0.19 \%$. However, the standard deviation of the tension of the line 2 at the fairlead also increases $1.8 \%$.

The Figure 12 shows a time series section of the tensions of Fairlead 2. An increase of the vibration of the tension due to the wave forces acting on the mooring lines is noticed. These vibrations are better noticed in the PSD plots of the tensions of the mooring lines 1 and 2 (Figure 13) for frequencies larger than $0.32 \mathrm{~Hz}$ and produce a better fitting of the experimental data.

The wave forces on the mooring lines have little influence on the forces at the tower base as shown in Table 9. The differences are less than $0.4 \%$ for the maximum forces, and less than $0.55 \%$ for the standard deviation. These differences are much lower than the differences of the tensions at the fairleads.

Table 9: Tension Fairlead and Tower Base forces Summary of DeepCWind Simulations

\begin{tabular}{|l|c|c|c|c|c|c|}
\hline Fairlead1 & $\boldsymbol{m i n}$ & $\boldsymbol{m e a n}$ & $\boldsymbol{m a x}$ & $\Delta \boldsymbol{m a x}(\%)$ & $\boldsymbol{\sigma}$ & $\Delta \boldsymbol{\sigma}(\%)$ \\
\hline $\begin{array}{l}\text { No Mooring } \\
\text { Hydrodynamics }\end{array}$ & $390.67 \mathrm{kN}$ & $1031.81 \mathrm{kN}$ & $1533.03 \mathrm{kN}$ & & $89.23 \mathrm{kN}$ & \\
\hline $\begin{array}{l}\text { Mooring } \\
\text { Hydrodynamics }\end{array}$ & $367.32 \mathrm{kN}$ & $1030.67 \mathrm{kN}$ & $1554.48 \mathrm{kN}$ & $1.40 \%$ & $92.98 \mathrm{kN}$ & $4.20 \%$ \\
\hline Fairlead2 & $\boldsymbol{m i n}$ & $\boldsymbol{m e a n}$ & $\boldsymbol{m a x}$ & $\Delta \max (\%)$ & $\boldsymbol{\sigma}$ & $\Delta \boldsymbol{\sigma}(\%)$ \\
\hline $\begin{array}{l}\text { No Mooring } \\
\text { Hydrodynamics }\end{array}$ & $0.4683 \mathrm{kN}$ & $1232.821 \mathrm{~N}$ & $5353.26 \mathrm{kN}$ & & $440.80 \mathrm{kN}$ & \\
\hline $\begin{array}{l}\text { Mooring } \\
\text { Hydrodynamics }\end{array}$ & $3.4447 \mathrm{kN}$ & $1232.90 \mathrm{kN}$ & $5343.15 \mathrm{kN}$ & $-0.19 \%$ & $448.87 \mathrm{kN}$ & $1.83 \%$ \\
\hline Fairlead3 & $\boldsymbol{m i n}$ & $\boldsymbol{m e a n}$ & $\boldsymbol{m a x}$ & $\Delta \max (\%)$ & $\boldsymbol{\sigma}$ & $\Delta \boldsymbol{\sigma}(\%)$ \\
\hline $\begin{array}{l}\text { No Mooring } \\
\text { Hydrodynamics }\end{array}$ & $420.61 \mathrm{kN}$ & $1102.61 \mathrm{kN}$ & $1659.80 \mathrm{kN}$ & & $98.94 \mathrm{kN}$ & \\
\hline
\end{tabular}




\begin{tabular}{|l|c|c|c|c|c|c|}
\hline $\begin{array}{l}\text { Mooring } \\
\text { Hydrodynamics }\end{array}$ & $387.32 \mathrm{kN}$ & $1101.46 \mathrm{kN}$ & $1684.55 \mathrm{kN}$ & $1.49 \%$ & $103.17 \mathrm{kN}$ & $4.28 \%$ \\
\hline TwrBsFxt & $\boldsymbol{m i n}$ & $\boldsymbol{m e a n}$ & $\max$ & $\Delta \max (\%)$ & $\boldsymbol{\sigma}$ & $\Delta \boldsymbol{\sigma}(\%)$ \\
\hline $\begin{array}{l}\text { No Mooring } \\
\text { Hydrodynamics }\end{array}$ & $-2315.01 \mathrm{kN}$ & $96.5914 \mathrm{kN}$ & $2220.768 \mathrm{kN}$ & & $408.544 \mathrm{kN}$ & \\
\hline $\begin{array}{l}\text { Mooring } \\
\text { Hydrodynamics }\end{array}$ & $-2319.6 \mathrm{kN}$ & $95.9656 \mathrm{kN}$ & $2224.82 \mathrm{kN}$ & $0.18 \%$ & $410.7606 \mathrm{kN}$ & $0.54 \%$ \\
\hline TwrBsMyt & $\boldsymbol{m i n}$ & $\boldsymbol{m e a n}$ & $\max$ & $\Delta \max (\%)$ & $\boldsymbol{\sigma}$ & $\Delta \boldsymbol{\sigma}(\%)$ \\
\hline $\begin{array}{l}\text { No Mooring } \\
\text { Hydrodynamics }\end{array}$ & $-190304 \mathrm{kN} \cdot \mathrm{m}$ & $-271.479 \mathrm{kN} \cdot \mathrm{m}$ & $158900.4 \mathrm{kN} \cdot \mathrm{m}$ & & $31304.67 \mathrm{kN} \cdot \mathrm{m}$ & \\
\hline $\begin{array}{l}\text { Mooring } \\
\text { Hydrodynamics }\end{array}$ & $-190998 \mathrm{kN} \cdot \mathrm{m}$ & $-310.272 \mathrm{kN} \cdot \mathrm{m}$ & $159523.9 \mathrm{kN} \cdot \mathrm{m}$ & $0.39 \%$ & $31463.87 \mathrm{kN} \cdot \mathrm{m}$ & $0.51 \%$ \\
\hline
\end{tabular}

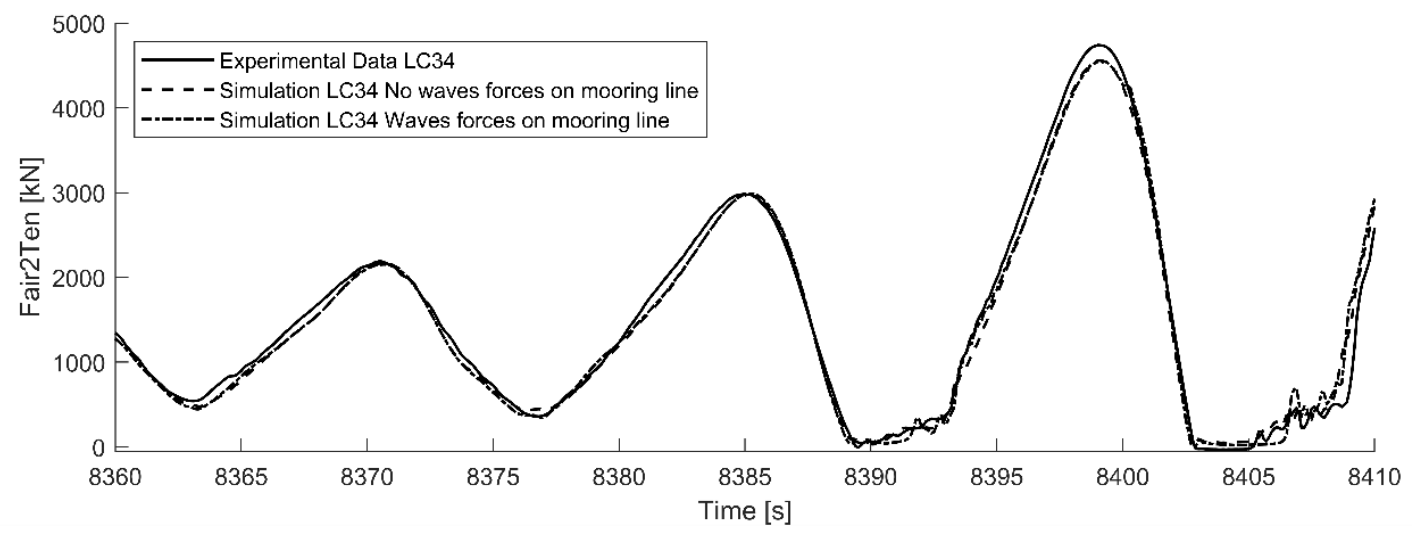

Figure 12: Fairlead2 tension time segment
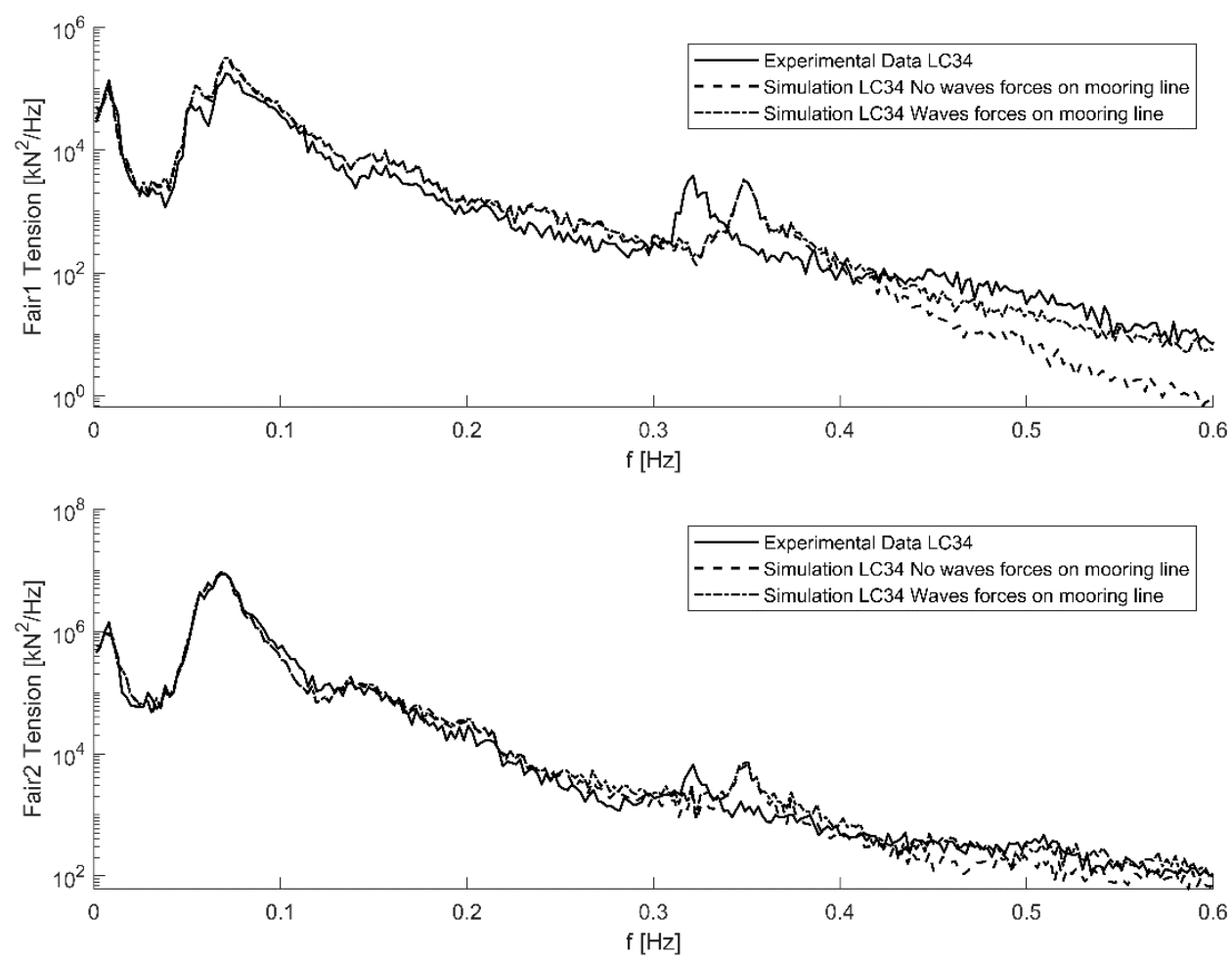


\subsection{OC3 Hywind}

The OC3.Spar Hywind platform is a steel spar platform coupled with the NREL 5MW reference wind turbine studied within the Phase IV of the OC3 project [12]. The model is analyzed subjected to a normal sea state for operational condition and to a severe sea state, both in Power Production State with a dynamic wind with a mean speed of $13.05 \mathrm{~m} / \mathrm{s}$, see Table 10 for more details. The wave elevation are get from OC5 tsk II project [10], but the kinematics are updated accounting for the variation of the sea depth of the OC3 Hywind.

Table 10: Description of the LC for the OC3 Hywind analysis

\begin{tabular}{|c|c|c|c|c|c|c|}
\hline Load Case & Description & RPM & $\begin{array}{c}\text { Blade Pitch } \\
\text { (deg) }\end{array}$ & Wave Condition & $\begin{array}{c}\text { Wind } \\
\text { Condition }\end{array}$ & $\begin{array}{c}\text { Sim. Length } \\
\text { (min) }\end{array}$ \\
\hline $\begin{array}{c}\text { OC3 Hywind } \\
\text { Operational } \\
\text { Case }\end{array}$ & $\begin{array}{c}\text { Operational } \\
\text { Wave }\end{array}$ & Variable & Variable & $\begin{array}{c}\text { Irregular: } H_{s}=7.1 \mathrm{~m}, T_{p} \\
=12.1 \mathrm{~s}, \gamma=2.2, \\
\text { JONSWAP }\end{array}$ & $\begin{array}{c}\text { NPD } \\
\text { spectrum, } \\
\mu=13.05\end{array}$ & 180 \\
\hline $\begin{array}{c}\text { OC3 Hywind } \\
\text { Design Case }\end{array}$ & Design Wave & Variable & Variable & $\begin{array}{c}\text { Irregular: } H_{s}=10.5 \mathrm{~m}, \\
T_{p}=14.3 \mathrm{~s}, \gamma=3.0, \\
\text { JONSWAP }\end{array}$ & $\begin{array}{c}\text { NPD } \\
\text { spectrum, } \\
\mu=13.05\end{array}$ & 180 \\
\hline
\end{tabular}

The Hywind simulations are performed by four different fairlead positions and, again, with and without the wave hydrodynamic loads over the lines. These points are equal distributed from the actual fairlead depth to the MSL at a depths of $-70,-47,-23$ and $0 \mathrm{~m}$. Then, in order to maintain the same mooring system shape, the seabed is also shifted as the fairlead offset. Then, the forces developed by the mooring system are equivalent. However, it is expected that the platform reduces the mean pitch rotation due to the increase of the restoring moment due to the mooring forces. Moreover, the fairlead position will be influenced by the coupling of the pitch and surge motion of the platform, and an increase of the tension range for higher fairlead positions is expected. However, the study focuses in the differences between considering or not the wave forces on the mooring line for each individual fairlead position case.

The Figure 14 shows a sketch of the set-up of the OC3 Hywind model varying the fairlead position and the corresponding seabed depth. This study is intended to assess the contribution of the wave loads on the mooring lines depending on their depth. To make easier the differentiation of the models for each fairlead position, these are identified as $\mathrm{C} 70$ for the actual fairlead position at $-70 \mathrm{~m}, \mathrm{C} 47$ for the fairlead positioned at $-47 \mathrm{~m}$ depth, $\mathrm{C} 23$ for the fairlead at $-23 \mathrm{~m}$ and $\mathrm{CO}$ for the fairlead depth at the MSL. 


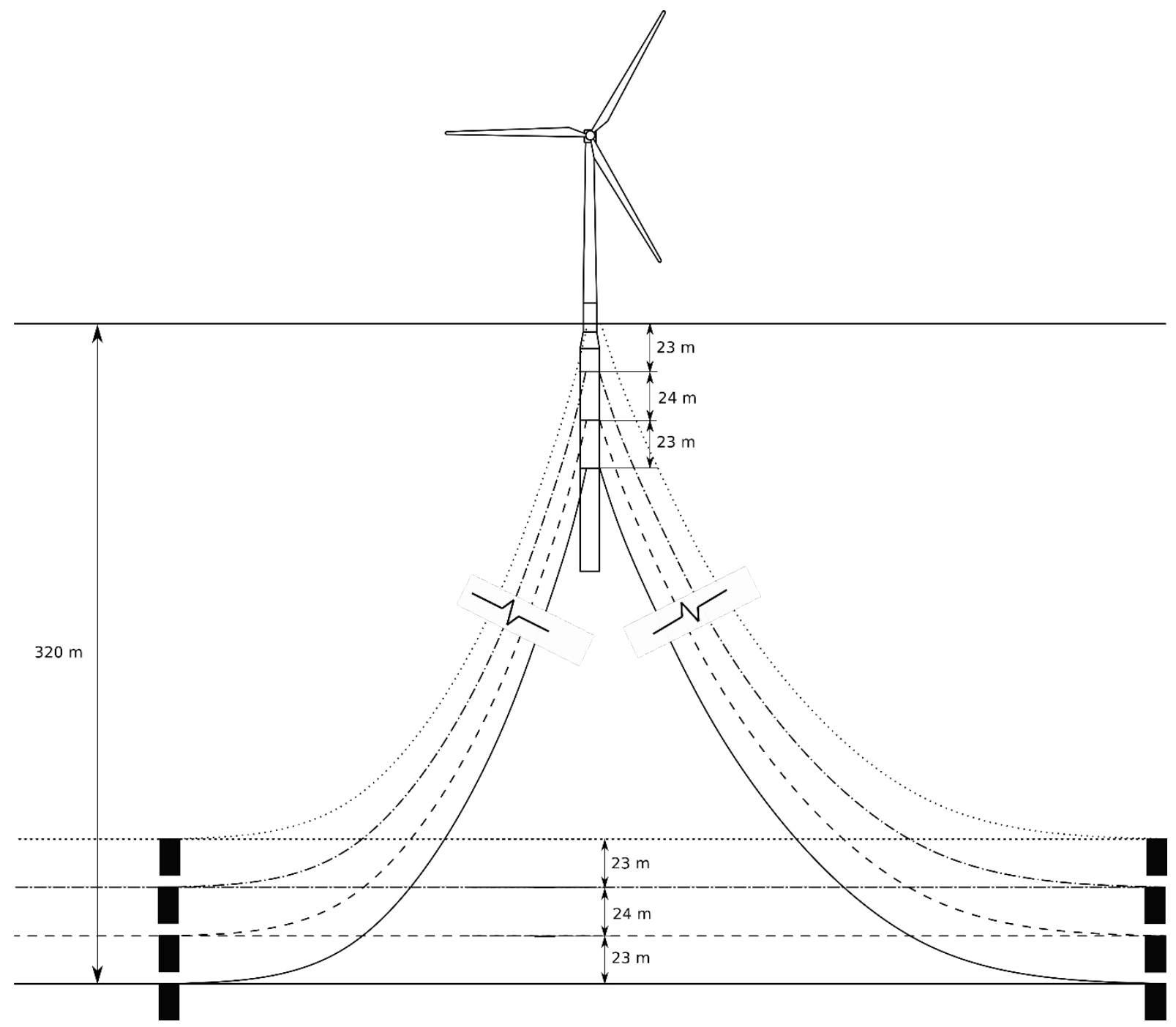

Figure 14: Sketch of OC3 Hywind

\subsubsection{OC3 Hywind Spar Model}

\section{Structural properties}

The Hywind platform wind turbine structure is discretized from $-120 \mathrm{~m}$ up to 10 in 64 beam elements. The remaining $77 \mathrm{~m}$ of tower are discretized in 16 elements. A finer discretization of the submerged part is used to improve the assessment of the hydrodynamics loads. The total amount of beam elements is 80 .

The density of the beam elements is set to $8500 \mathrm{~kg} / \mathrm{m}^{3}$ to take into account paint, bolts, welds, stiffeners and flanges of the structure. The tower is defined as presented in [12] with a tapered section from a base diameter of $6.5 \mathrm{~m}$ and $0.027 \mathrm{~m}$ thickness, to a top diameter of $3.87 \mathrm{~m}$ and $0.019 \mathrm{~m}$ thickness. The buoy is divided in three parts, a lower cylinder, the tapper section and the top cylinder. The draft of the buoy is $120 \mathrm{~m}$, the depth of the bottom of the tapper is $12 \mathrm{~m}$, the depth of the top of the tapper is $4 \mathrm{~m}$, and the top cylinder ends at $10 \mathrm{~m}$ above the SWL. The diameter of the buoy changes at the tapper section from $9.4 \mathrm{~m}$ to $6.5 \mathrm{~m}$, and the thickness is considered constant.

The thickness of the buoy and the height and bulk density of the ballast are deduced from an optimization problem to fit the given values of the mass, the CoG and the inertias of the OC3 Hywind shown in Table 11. The thickness of 
the platform is set to $0.0365 \mathrm{~m}$, the height of the ballast to $49 \mathrm{~m}$ with a bulk density of $1890 \mathrm{~kg} / \mathrm{m}^{3}$. These values lack Yaw Inertia of $7.1703 \mathrm{E}+07 \mathrm{~kg} \cdot \mathrm{m}^{2}$ that was added at the CoG.

Table 11: OC3 Hywind platform characteristics [12]

\section{Hydrodynamic Properties}

\begin{tabular}{|l|l|}
\hline Draft [m] & 120 \\
\hline Platform Diameter above Taper [m] & 6.5 \\
\hline Platform Diameter below Taper [m] & 9.4 \\
\hline Platform Mass, including Ballast [kg] & $7.466 \mathrm{E}+06$ \\
\hline CM Location Below SWL [m] & 89.92 \\
\hline Platform Roll/Pitch Inertia [kg/m $\left.{ }^{2}\right]$ & $4.229 \mathrm{E}+09$ \\
\hline Platform Yaw Inertia $\left[\mathrm{kg} / \mathbf{m}^{2}\right]$ & $1.642 \mathrm{E}+08$ \\
\hline
\end{tabular}

The hydrodynamic properties of the platform are based on the Morison equation[21] as only beam elements are considered. The hydrodynamic properties are divided in the bottom plate, the cylinders and the tapper transition as shown in Table 12 which are obtained from standard values used in the industry and research [26].

The bottom plate hydrodynamics are based on the drag normal to the plate, and the added mass proportional to volume of the half-hemisphere referent to the plate radius. The dynamic pressure is taken into account via the wave pressure. The hydrodynamics of the cylinders are defined by the transverse drag and the transverse added mass coefficient. On the other hand, the tapper section hydrodynamics accounts for the transverse drag, the transverse added mass, and the longitudinal added mass as well. However, the axial drag term of the tap section is not considered because all longitudinal drag terms are assessed at the bottom plate.

The platform hydrodynamic coefficients are as follows:

Table 12: Hydrodynamic Parameters of OC3 Hywind Platform

\begin{tabular}{|l|l|l|l|l|l|l|}
\cline { 2 - 7 } \multicolumn{1}{c|}{} & \multicolumn{2}{l|}{$\mathrm{C}_{\mathrm{d}}$} & \multicolumn{2}{l|}{$\mathrm{C}_{\mathrm{a}}$} & \multicolumn{2}{l|}{$\mathrm{C}_{\mathrm{m}}$} \\
\cline { 2 - 8 } \multicolumn{1}{c|}{} & Trans & Long. & Trans & Long. & Trans & Long. \\
\hline Bottom plate & -- & 2 & -- & 1 & -- & -- \\
\hline Cylinder & 0.6 & -- & 0.97 & -- & 1.97 & -- \\
\hline Tapper section & 0.6 & -- & 0.97 & 1 & 1.97 & 1 \\
\hline
\end{tabular}

\section{Mooring Properties}

The characteristics of the mooring lines shown in Table 13 are based on the same properties proposed by [12]. The hydrodynamic properties are the same as the DeepCWind simulations of section 4.1.1 due to the lack of information and experimental results. The delta mooring system is simulated by an additional yaw spring stiffness of $98.34 \cdot 10^{6} \mathrm{~N} \cdot \mathrm{m} / \mathrm{rad}$ at the centroid of the fairleads positions. 


\begin{tabular}{|l|l|}
\hline No of mooring lines & 3 \\
\hline Depth of Anchors [m] & 320 \\
\hline Depth of Fairleads [m] & 70 \\
\hline Radius to Anchors [m] & 853.87 \\
\hline Radius to Fairlead [m] & 5.2 \\
\hline Unstretched mooring line length [m] & 902 \\
\hline Mooring line diameter [m] & 0.09 \\
\hline Mooring line density [kg/m] & 77.71 \\
\hline Mooring line wet weight [N/m] & 698.1 \\
\hline Mooring line Extensional Stiffness (EA) [N] & $3.842 \mathrm{E}+08$ \\
\hline Cdt & 0.86 \\
\hline Cdn & 1.875 \\
\hline Ca & 0.5 \\
\hline$\xi_{A}$ & $3 \%$ \\
\hline & \\
\hline
\end{tabular}

\section{Wind Turbine Properties}

The wind turbine used is the NREL $5 \mathrm{MW}$ reference wind turbine [27]. The blade pitch control is based on a generator-torque control strategy in the above rated torque region with a natural frequency pitch-controllerresponse below the platform pitch natural frequency [4].

\subsubsection{Simulation Results Analysis}

The effect of the hydrodynamic forces of the wave train over the mooring lines are conditioned for the depth of the fairleads was as expected. Table 14 and Table 15 show a summary of the simulation results, comparing the minimum, mean, maximum values and the standard deviation $(\sigma)$ of the tension at the fairleads for the four cases with and without wave hydrodynamics over the mooring lines for the operational and design cases. However, results coming from different fairlead positions have to be compared very carefully, as the fairlead position affects clearly the tension range of the lines. Higher fairleads are more separated from the center of gravity of the structure leading to an increment of the surge motion amplitude of the fairleads, due to the platform pitch. Then, even the mean tension is almost constant for all the four cases, the lower fairlead depth, the larger tension range.

The tension results are presented for each fairlead, where the fairlead 1 is the one attached to the line placed along the wave spread direction. Fairleads 2 and 3 are attached to the lines positioned \pm 120 o respect to the wave direction.

The results for the operational and design cases show a clear tendency to widening the mooring line tension range when the wave loads on mooring lines are considered. The minimum tension tends to decrease and the peak tension tends to increase. Then, the standard deviation of the tension also increases. Moreover, the increase of the standard deviation is larger for the higher fairlead positions, as the wave loads decrease exponentially with the depth.

The standard deviation of the tension in the operation load case increases when the wave loads on mooring lines are considered. For the lower fairlead positions, C70 and C47 the differences are less than $1 \%$. However, for the CO case, the standard deviation increases $0.56 \%$ for the fairlead 1 and about $2.8 \%$ for the fairleads 2 and 3 . However, these increments are lower than for the design load case.

The design load case presents larger hydrodynamic forces than the operational one and, then, presents larger differences between the simulations when wave loads on moorings are included. The increase of the standard deviation of the tension of the fairlead 1 goes from $0.18 \%$ (C70) to $1.56 \%$ (C0). For the fairleads 2 and 3 , the increase of the standard deviation goes from $1.21 \%$ (C70) to 5.53\% (C0). Taking a close look at results obtained for 
the design load case, the Fairlead 1 presents a slack phenomenon in C43, C32 and C0, affecting the maximum tension in the simulations.

At the $\mathrm{C} 43$ and $\mathrm{C} 23$ of the design load case, the minimum tension of fairlead 1clearly decreases and its maximum value is almost unaltered. In these cases, the slack-snap phenomenon appears in some points of the mooring line which governs the behavior of the line, then the maximum tension does not change. However, fairleads 2 and 3 do not suffer slack events and the maximum tensions increase, as was expected.

At the $\mathrm{CO}$ of the design load case also appears a slack-snap tension phenomenon on the fairlead 1 as shown in Figure 15. Then, the minimum tension at Fairlead 1 goes to zero. Even though this event, the maximum tension at the Fairlead 1 also increases, while in C47 and C23 changes are very small. This fact can be explained due to the line being exposed to the most energetic region close to the MSL, thus even the mooring line tension is mainly governed by this event and, as such the wave hydrodynamics cannot be despicable. Moreover, the tension of the lines are excited in the higher frequency ranges (Figure 15) as was also noticed in the DeepCWind mooring lines (Figure 13). However, the energy of these vibrations are orders of magnitude smaller than those that produce the tension changes, despite being experimentally confirmed (Figure 13).
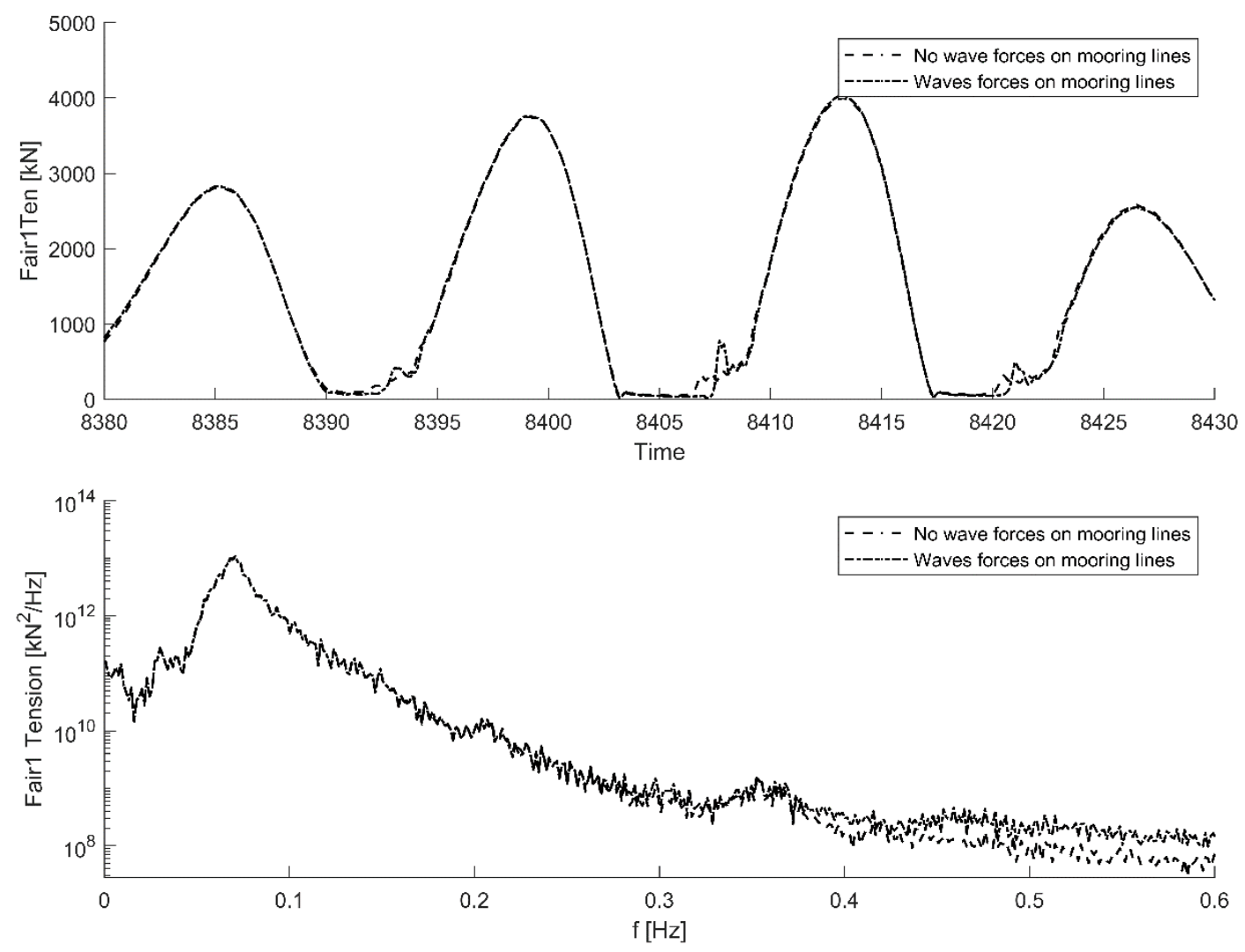

Figure 15: Time Series (Up) and PSD (Down) of CO Fairlead Tension 
Table 14: OC3 Hywind Simulation Results for the operational case

\begin{tabular}{|c|c|c|c|c|c|c|}
\hline \multicolumn{7}{|l|}{ C70: Fairlead depth of $-70 \mathrm{~m}$} \\
\hline Fairlead1 & $\min$ & mean & $\max$ & $\Delta \max (\%)$ & $\sigma$ & $\Delta \boldsymbol{\sigma}(\%)$ \\
\hline No Mooring Hydrodynamics & 916.40 & 1270.76 & 1655.75 & & 70.11 & \\
\hline Mooring Hydrodynamics & 914.72 & 1270.69 & 1653.70 & $-0.12 \%$ & 70.13 & $0.03 \%$ \\
\hline Fairlead2 & $\min$ & mean & $\max$ & $\Delta \max (\%)$ & $\sigma$ & $\Delta \boldsymbol{\sigma}(\%)$ \\
\hline No Mooring Hydrodynamics & 673.09 & 773.36 & 846.85 & & 15.46 & \\
\hline Mooring Hydrodynamics & 672.49 & 773.37 & 847.32 & $0.05 \%$ & 15.49 & $0.23 \%$ \\
\hline Fairlead3 & $\min$ & mean & $\max$ & $\Delta \max (\%)$ & $\sigma$ & $\Delta \boldsymbol{\sigma}(\%)$ \\
\hline No Mooring Hydrodynamics & 681.26 & 786.17 & 861.24 & & 16.25 & \\
\hline Mooring Hydrodynamics & 680.74 & 786.18 & 861.58 & $0.04 \%$ & 16.29 & $0.25 \%$ \\
\hline \multicolumn{7}{|l|}{ C47: Fairlead depth of $-47 \mathrm{~m}$} \\
\hline Fairlead1 & $\min$ & mean & $\max$ & $\Delta \max (\%)$ & $\sigma$ & $\Delta \boldsymbol{\sigma}(\%)$ \\
\hline No Mooring Hydrodynamics & 640.76 & 1283.11 & 2011.36 & & 118.78 & \\
\hline Mooring Hydrodynamics & 637.23 & 1283.04 & 2016.52 & $0.26 \%$ & 118.75 & $-0.03 \%$ \\
\hline Fairlead2 & $\min$ & mean & $\max$ & $\Delta \max (\%)$ & $\sigma$ & $\Delta \boldsymbol{\sigma}(\%)$ \\
\hline No Mooring Hydrodynamics & 616.64 & 776.30 & 891.69 & & 21.58 & \\
\hline Mooring Hydrodynamics & 615.05 & 776.28 & 892.63 & $0.11 \%$ & 21.68 & $0.45 \%$ \\
\hline Fairlead3 & $\min$ & mean & $\max$ & $\Delta \max (\%)$ & $\sigma$ & $\Delta \boldsymbol{\sigma}(\%)$ \\
\hline No Mooring Hydrodynamics & 620.52 & 788.91 & 911.18 & & 22.75 & \\
\hline Mooring Hydrodynamics & 619.18 & 788.89 & 912.17 & $0.11 \%$ & 22.85 & $0.46 \%$ \\
\hline \multicolumn{7}{|l|}{ C23: Fairlead depth of $-23 \mathrm{~m}$} \\
\hline Fairlead1 & $\min$ & mean & $\max$ & $\Delta \max (\%)$ & $\sigma$ & $\Delta \boldsymbol{\sigma}(\%)$ \\
\hline No Mooring Hydrodynamics & 295.58 & 1293.09 & 2503.72 & & 165.15 & \\
\hline Mooring Hydrodynamics & 269.13 & 1293.00 & 2503.34 & $-0.01 \%$ & 165.39 & $0.14 \%$ \\
\hline Fairlead2 & $\min$ & mean & $\max$ & $\Delta \max (\%)$ & $\sigma$ & $\Delta \boldsymbol{\sigma}(\%)$ \\
\hline No Mooring Hydrodynamics & 530.49 & 775.56 & 934.31 & & 29.38 & \\
\hline Mooring Hydrodynamics & 526.35 & 775.55 & 936.88 & $0.28 \%$ & 29.68 & $0.99 \%$ \\
\hline Fairlead3 & $\min$ & mean & $\max$ & $\Delta \max (\%)$ & $\sigma$ & $\Delta \boldsymbol{\sigma}(\%)$ \\
\hline No Mooring Hydrodynamics & 532.17 & 787.88 & 944.64 & & 30.79 & \\
\hline Mooring Hydrodynamics & 528.08 & 787.86 & 947.15 & $0.27 \%$ & 31.11 & $1.01 \%$ \\
\hline \multicolumn{7}{|c|}{ C0: Fairlead depth of Om for LC33 } \\
\hline Fairlead1 & $\min$ & mean & $\max$ & $\Delta \max (\%)$ & $\sigma$ & $\Delta \boldsymbol{\sigma}(\%)$ \\
\hline No Mooring Hydrodynamics & 95.99 & 1299.39 & 2870.76 & & 210.91 & \\
\hline Mooring Hydrodynamics & 81.47 & 1299.51 & 2868.08 & $-0.09 \%$ & 212.09 & $0.56 \%$ \\
\hline Fairlead2 & $\min$ & mean & $\max$ & $\Delta \max (\%)$ & $\sigma$ & $\Delta \boldsymbol{\sigma}(\%)$ \\
\hline No Mooring Hydrodynamics & 495.53 & 776.89 & 997.45 & & 33.85 & \\
\hline Mooring Hydrodynamics & 482.70 & 776.87 & 1003.28 & $0.58 \%$ & 34.79 & $2.77 \%$ \\
\hline Fairlead3 & $\min$ & mean & $\max$ & $\Delta \max (\%)$ & $\sigma$ & $\Delta \boldsymbol{\sigma}(\%)$ \\
\hline No Mooring Hydrodynamics & 498.99 & 788.91 & 1006.16 & & 35.41 & \\
\hline Mooring Hydrodynamics & 483.10 & 788.88 & 1011.82 & $0.56 \%$ & 36.39 & $2.79 \%$ \\
\hline
\end{tabular}


Table 15: OC3 Hywind Simulation Results for the design case.

\begin{tabular}{|c|c|c|c|c|c|c|}
\hline \multicolumn{7}{|l|}{ C70: Fairlead depth of $-70 \mathrm{~m}$} \\
\hline Fairlead1 & $\min$ & mean & $\max$ & $\Delta \max (\%)$ & $\sigma$ & $\Delta \boldsymbol{\sigma}(\%)$ \\
\hline No Mooring Hydrodynamics & 475.53 & 1282.31 & 2228.91 & & 137.27 & \\
\hline Mooring Hydrodynamics & 453.36 & 1282.36 & 2230.45 & $0.07 \%$ & 137.52 & $0.18 \%$ \\
\hline Fairlead2 & $\min$ & mean & $\max$ & $\Delta \max (\%)$ & $\sigma$ & $\Delta \boldsymbol{\sigma}(\%)$ \\
\hline No Mooring Hydrodynamics & 542.66 & 781.30 & 958.17 & & 28.94 & \\
\hline Mooring Hydrodynamics & 543.05 & 781.27 & 956.59 & $-0.17 \%$ & 29.29 & $1.21 \%$ \\
\hline Fairlead3 & $\min$ & mean & $\max$ & $\Delta \max (\%)$ & $\sigma$ & $\Delta \sigma(\%)$ \\
\hline No Mooring Hydrodynamics & 548.49 & 793.28 & 974.65 & & 29.82 & \\
\hline Mooring Hydrodynamics & 548.87 & 793.25 & 972.00 & $-0.27 \%$ & 30.18 & $1.21 \%$ \\
\hline \multicolumn{7}{|l|}{ C47: Fairlead depth of $-47 \mathrm{~m}$} \\
\hline Fairlead1 & $\min$ & mean & $\max$ & $\Delta \max (\%)$ & $\sigma$ & $\Delta \boldsymbol{\sigma}(\%)$ \\
\hline No Mooring Hydrodynamics & 167.31 & 1289.82 & 2969.07 & & 224.62 & \\
\hline Mooring Hydrodynamics & 106.89 & 1289.69 & 2969.67 & $0.02 \%$ & 225.50 & $0.39 \%$ \\
\hline Fairlead2 & $\min$ & mean & $\max$ & $\Delta \max (\%)$ & $\sigma$ & $\Delta \boldsymbol{\sigma}(\%)$ \\
\hline No Mooring Hydrodynamics & 377.35 & 779.31 & 1014.72 & & 40.69 & \\
\hline Mooring Hydrodynamics & 372.04 & 779.27 & 1019.13 & $0.43 \%$ & 41.53 & $2.06 \%$ \\
\hline Fairlead3 & $\min$ & mean & $\max$ & $\Delta \max (\%)$ & $\sigma$ & $\Delta \boldsymbol{\sigma}(\%)$ \\
\hline No Mooring Hydrodynamics & 372.42 & 791.23 & 1029.27 & & 42.21 & \\
\hline Mooring Hydrodynamics & 366.82 & 791.19 & 1032.74 & $0.34 \%$ & 43.07 & $2.02 \%$ \\
\hline \multicolumn{7}{|l|}{ C23: Fairlead depth of $-23 \mathrm{~m}$} \\
\hline Fairlead1 & $\min$ & mean & $\max$ & $\Delta \max (\%)$ & $\sigma$ & $\Delta \boldsymbol{\sigma}(\%)$ \\
\hline No Mooring Hydrodynamics & 65.38 & 1299.05 & 3601.40 & & 327.38 & \\
\hline Mooring Hydrodynamics & 38.44 & 1298.77 & 3601.17 & $-0.01 \%$ & 330.21 & $0.87 \%$ \\
\hline Fairlead2 & $\min$ & mean & $\max$ & $\Delta \max (\%)$ & $\sigma$ & $\Delta \boldsymbol{\sigma}(\%)$ \\
\hline No Mooring Hydrodynamics & 311.18 & 777.57 & 1125.54 & & 54.27 & \\
\hline Mooring Hydrodynamics & 291.34 & 777.40 & 1129.93 & $0.39 \%$ & 55.97 & $3.14 \%$ \\
\hline Fairlead3 & $\min$ & mean & $\max$ & $\Delta \max (\%)$ & $\sigma$ & $\Delta \boldsymbol{\sigma}(\%)$ \\
\hline No Mooring Hydrodynamics & 311.87 & 789.51 & 1144.21 & & 56.28 & \\
\hline Mooring Hydrodynamics & 291.82 & 789.34 & 1147.19 & $0.26 \%$ & 58.02 & $3.09 \%$ \\
\hline \multicolumn{7}{|l|}{ C0: Fairlead depth of $0 \mathrm{~m}$} \\
\hline Fairlead1 & $\min$ & mean & $\max$ & $\Delta \max (\%)$ & $\sigma$ & $\Delta \boldsymbol{\sigma}(\%)$ \\
\hline No Mooring Hydrodynamics & 9.65 & 1309.66 & 4137.04 & & 447.60 & \\
\hline Mooring Hydrodynamics & 0.00 & 1309.97 & 4154.54 & $0.42 \%$ & 454.59 & $1.56 \%$ \\
\hline Fairlead2 & $\min$ & mean & $\max$ & $\Delta \max (\%)$ & $\sigma$ & $\Delta \boldsymbol{\sigma}(\%)$ \\
\hline No Mooring Hydrodynamics & 268.28 & 776.29 & 1202.46 & & 66.50 & \\
\hline Mooring Hydrodynamics & 220.71 & 775.89 & 1207.73 & $0.44 \%$ & 70.18 & $5.53 \%$ \\
\hline Fairlead3 & $\min$ & mean & $\max$ & $\Delta \max (\%)$ & $\sigma$ & $\Delta \boldsymbol{\sigma}(\%)$ \\
\hline No Mooring Hydrodynamics & 259.47 & 788.16 & 1228.10 & & 69.07 & \\
\hline Mooring Hydrodynamics & 209.74 & 787.78 & 1231.16 & $0.25 \%$ & 72.44 & $4.87 \%$ \\
\hline
\end{tabular}




\subsubsection{Fatigue Analysis}

A sensibility fatigue analysis is carried out from the data of the operational and design load cases of the fairlead tensions for each fairlead case. The aim of the analysis is to assess the contribution of the wave loads on the fatigue life of the mooring lines. The fatigue analysis is performed using DNV-GL mooring standard [9] and the rainflow count to obtain the tension range. The damage of the mooring in a state $\mathrm{i}\left(d_{i}\right)$ line is assessed by Eq.(11).

$$
d_{i}=\frac{n_{i}}{a_{D}} E\left[S_{i}^{m}\right]
$$

Where, $n_{i}$ is the number of stress cycles, $a_{D}$ is the intercept parameter of the S-N curve, $m$ is the slope of the S-N curve, and $E\left[S_{i}^{m}\right]$ is the expected value of expected value of the nominal stress ranges raised to the power $\mathrm{m}$ in state i.

Supposing the mooring line is a studless chain, the $a_{D}$ is set to $6.0 \mathrm{E}+10$ and $m$ is set to 3 . In this case, the corrosion allowance is not taken into account, and the diameter of the chain is set to $90 \mathrm{~mm}$.

Table 16 and Table 17 show the results of the fatigue analysis of the moorings. When the wave loads on the moorings are included, the damage of the lines increase due to the increment of the tension range at the fairleads.

Fairlead 1 is the most damaged line due to its alignment with the wave train, which implies a larger stress range. The contribution of the wave hydrodynamic forces on the damage of the line 1 is an increment from $0 \%$ to $3 \%$ for the operational load case and from a $1.3 \%$ to a $5.1 \%$ for design load case. Fairlead 2 and 3 suffer a larger percentage increment from $1 \%$ to $9 \%$ for the operational case and from $2.6 \%$ to a $20.2 \%$ for the design case. This larger percentage increase of the Fairleads 2 and 3 are due to the damage is very limited if the wave loads on mooring lines are not considered.

Table 16: Fatigue sensibility study for the OC3 Hywind operational load case

\begin{tabular}{|c|c|c|c|c|c|c|c|c|c|}
\hline & & \multicolumn{2}{|l|}{ C70 } & \multicolumn{2}{|l|}{ C47 } & \multicolumn{2}{|l|}{ C23 } & \multicolumn{2}{|l|}{ CO } \\
\hline & & $d$ & $\Delta d(\%)$ & $d$ & $\Delta d(\%)$ & $d$ & $\Delta d(\%)$ & $d$ & $\Delta d(\%)$ \\
\hline \multirow{2}{*}{ Fairlead1 } & $\begin{array}{l}\text { No Mooring } \\
\text { Hydrodynamics }\end{array}$ & $6.22 \mathrm{E}-05$ & & $3.70 \mathrm{E}-04$ & & $1.09 \mathrm{E}-03$ & & $2.42 \mathrm{E}-03$ & \\
\hline & $\begin{array}{l}\text { Mooring } \\
\text { Hydrodynamics }\end{array}$ & $6.22 \mathrm{E}-05$ & $0.1 \%$ & $3.70 \mathrm{E}-04$ & $0.1 \%$ & $1.10 \mathrm{E}-03$ & $0.9 \%$ & $2.48 \mathrm{E}-03$ & $2.6 \%$ \\
\hline \multirow{2}{*}{ Fairlead2 } & $\begin{array}{l}\text { No Mooring } \\
\text { Hydrodynamics }\end{array}$ & $7.52 \mathrm{E}-07$ & & $2.66 \mathrm{E}-06$ & & $7.14 \mathrm{E}-06$ & & $1.16 \mathrm{E}-05$ & \\
\hline & $\begin{array}{l}\text { Mooring } \\
\text { Hydrodynamics }\end{array}$ & $7.58 \mathrm{E}-07$ & $0.8 \%$ & $2.70 \mathrm{E}-06$ & $1.3 \%$ & $7.31 \mathrm{E}-06$ & $2.4 \%$ & $1.26 \mathrm{E}-05$ & $8.3 \%$ \\
\hline \multirow{2}{*}{ Fairlead3 } & $\begin{array}{l}\text { No Mooring } \\
\text { Hydrodynamics }\end{array}$ & $8.51 \mathrm{E}-07$ & & $3.05 E-06$ & & 8.06E-06 & & $1.31 \mathrm{E}-05$ & \\
\hline & $\begin{array}{l}\text { Mooring } \\
\text { Hydrodynamics }\end{array}$ & $8.58 \mathrm{E}-07$ & $0.8 \%$ & $3.09 \mathrm{E}-06$ & $1.4 \%$ & $8.26 \mathrm{E}-06$ & $2.4 \%$ & $1.42 \mathrm{E}-05$ & $8.5 \%$ \\
\hline
\end{tabular}


Table 17: Fatigue sensibility study for the OC3 Hywind design load case

\begin{tabular}{|c|c|c|c|c|c|c|c|c|c|}
\hline & & \multicolumn{2}{|l|}{ C70 } & \multicolumn{2}{|l|}{ C47 } & \multicolumn{2}{|l|}{ C23 } & \multicolumn{2}{|l|}{ CO } \\
\hline & & $d$ & $\Delta d(\%)$ & $d$ & $\Delta d(\%)$ & $d$ & $\Delta d(\%)$ & $d$ & $\Delta d(\%)$ \\
\hline \multirow{2}{*}{ Fairlead1 } & $\begin{array}{l}\text { No Mooring } \\
\text { Hydrodynamics }\end{array}$ & $6.260 \mathrm{E}-04$ & & $2.684 \mathrm{E}-03$ & & 8.024E-03 & & $1.925 \mathrm{E}-02$ & \\
\hline & $\begin{array}{l}\text { Mooring } \\
\text { Hydrodynamics }\end{array}$ & $6.341 \mathrm{E}-04$ & $1.3 \%$ & $2.766 \mathrm{E}-03$ & $3.0 \%$ & $8.403 \mathrm{E}-03$ & $4.7 \%$ & $2.024 \mathrm{E}-02$ & $5.1 \%$ \\
\hline \multirow{2}{*}{ Fairlead2 } & $\begin{array}{l}\text { No Mooring } \\
\text { Hydrodynamics }\end{array}$ & 7.012E-06 & & $1.992 \mathrm{E}-05$ & & 4.744E-05 & & $9.045 \mathrm{E}-05$ & \\
\hline & $\begin{array}{l}\text { Mooring } \\
\text { Hydrodynamics }\end{array}$ & 7.197E-06 & $2.6 \%$ & 2.097E-05 & $5.3 \%$ & $5.145 \mathrm{E}-05$ & $8.5 \%$ & $1.087 \mathrm{E}-04$ & $20.2 \%$ \\
\hline \multirow{2}{*}{ Fairlead3 } & $\begin{array}{l}\text { No Mooring } \\
\text { Hydrodynamics }\end{array}$ & 7.479E-06 & & $2.181 \mathrm{E}-05$ & & $5.213 \mathrm{E}-05$ & & $1.038 \mathrm{E}-04$ & \\
\hline & $\begin{array}{l}\text { Mooring } \\
\text { Hydrodynamics }\end{array}$ & $7.682 \mathrm{E}-06$ & $2.7 \%$ & $2.295 \mathrm{E}-05$ & $5.2 \%$ & $5.645 \mathrm{E}-05$ & $8.3 \%$ & $1.147 \mathrm{E}-04$ & $10.5 \%$ \\
\hline
\end{tabular}

\section{Conclusions}

The influence of the wave hydrodynamics loads over the mooring system of FOWTs is appraised through the dynamic analysis of the moorings of two different concepts of floating platforms.

First, the simulation of an experiment allows the calibration of the numerical model including the wave hydrodynamic forces on the mooring line and, second, the assessment of the potential influence of the wave hydrodynamics over the total tension at the fairleads of a floating platform is presented. The results of the parametric study based on the experiment set-up show changes in the minimum maximum tension and also a clear increase of the standard deviation of the tension. Even though, a high-power regular wave train is used in the parametric analyses, those effects could be significant in irregular wave trains in full scale FOWT models. Also, it is found that larger chain diameters cause larger tension amplitudes that can affect the fatigue design of the mooring line.

The DeepCWind and the OC3 Hywind Spar platforms are simulated through different sea states. The results of the DeepCWind simulations show an increase of the standard deviation of the tension of $1.83 \%$ for the most loaded line, and of $4.25 \%$ for the less loaded lines.

A parametric study of the depth of the fairlead in the OC3 Hywind Spar platform allowed better analysis of the energy received from the wave loads. The study shows the effects of the increment of the wave load impact on the mooring if the fairleads are positioned closer to the MSL for an operational and a design sea state. The results show an increase of the standard deviation of the tension in the moorings, which means larger stress ranges which effects the fatigue design. The deeper the fairlead, the lower effect of the wave loads on the mooring line tensions. Moreover, a sensibility fatigue analysis is performed to assess the contribution of the wave loads on the damage of the lines. The results obtained for the OC3 Hywind Platform show an increase of 3\% and 5.1\% of the damage for the most loaded line for the operational and design sea states, which significantly reduce the service life of the line. Even for the actual fairlead position, a 70m depth, the wave loads also increase the damage about $1.3 \%$ for the design load case, whereas the damage is almost unaltered for the operational load case. For the lines not aligned to the wave train, the increment of the damage is larger than the standard deviation, but the total damaged suffered is lower due to a lower stress range.

In addition, it is stated that placing the fairleads far from the center of gravity of a floating platform may reduce the service life of the mooring system. The increment of motion of the fairleads due to the coupling of the surge 
and pitch motions increasing the tension range, and can double the maximum tension of the line by generating slack-snap phenomenon.

Currently, chain diameters and tendons used in FOWT are becoming larger which will make them more sensitive to wave loads. Then, there is a need to properly assess the tension on the mooring lines including the wave hydrodynamic forces on the mooring dynamics for a proper evaluation of the design life of the mooring system.

\section{References}

[1] IEA, “Offshore Energy Outlook," 2018.

[2] R. James and M. Costa, "Floating Offshore Wind : Market and Technology Review," United Kingdom, 2015.

[3] D. Matha, M. Schlipf, A. Cordle, R. Pereira, and J. Jonkman, "Challenges in Simulation of Aerodynamics , Hydrodynamics, and Mooring-Line Dynamics of Floating Offshore Wind Turbines," Eng. Conf., vol. 8, no. October, pp. 421-428, 2011.

[4] J. Jonkman and W. Musial, "IEA Wind Task 23 Offshore Wind Technology and Deployment Subtask 2 The Offshore Code Comparison Collaboration (OC3)." p. 74, 2010.

[5] E. Commission, P. Portal, and T. Commission, Horizon 2020 Work Programme 2018-2020 10. Secure, clean and efficient energy, vol. 2019, no. July 2018. 2020.

[6] A. Robertson and J. Jonkman, “Annex 30 - Task Extension Proposal , 2019-2022 Offshore Code Comparison Collaboration, Continued, with Correlation, and unCertainty ( OC6 ) 1 Scope," pp. 2019-2022, 2019.

[7] M. Masciola, A. Robertson, J. Jonkman, A. Coulling, and A. Goupee, "Assessment of the Importance of Mooring Dynamics on the Global Response of the DeepCwind Floating Semisubmersible Offshore Wind Turbine," 23th Int. Offshore Polar Eng., vol. 9, pp. 359-368, 2013.

[8] A. N. Robertson et al., "OC5 Project Phase II: Validation of Global Loads of the DeepCwind Floating Semisubmersible Wind Turbine," Energy Procedia, vol. 137, pp. 38-57, Oct. 2017.

[9] Det Norske Veritas, “Offshore Standard DNVGL-OS-E301 Position mooring,” no. July, 2015.

[10] A. N. Robertson, J. M. Jonkman, F. Wendt, A. Goupee, and H. Dagher, "Definition of the OC5 DeepCwind Semisubmersible Floating System," 2016.

[11] J. Helder and M. Pietersma, "DeepCwind/OC4 Semi Floating Wind Turbine Repeat Tests. MARIN Report No. 27005-1-OB," 2013.

[12] J. Jonkman, "Definition of the Floating System for Phase IV of OC3," Contract, vol. 1, no. May, p. $31,2010$.

[13] A. Campos, C. Molins, P. Trubat, and D. Alarcón, "A 3D FEM model for floating wind turbines support structures," in Energy Procedia, 2017, vol. 137, pp. 177-185.

[14] P. Trubat, A. Campos, C. Molins, and D. Alarcón, “OC5 task II simulations with FloaWDyn numerical model," in Proceedings of the International Offshore and Polar Engineering Conference, 2017.

[15] C. Felippa, "A systematic approach to the element-independent corotational dynamics of finite elements," Cent. Aerosp. Struct. Doc. Number ..., no. January, 2000.

[16] H. M. Hilber, T. J. R. Hughes, and R. L. Taylor, "Improved numerical dissipation for time integration algorithms in structural dynamics," Earthq. Eng. Struct. Dyn., no. 5, pp. 283-292, 1977.

[17] B. Jonkman and J. Jonkman, "FAST v8.16.00a-bjj," 2016.

[18] LHEEA, “NEMOH User's manual.” École Central de Nantes, Nantes (France), 2014. 
[19] D. L. Garrett, “Dynamic Analysis of Slender Rods," J. Energy Resour. Technol., vol. 104, no. 4, pp. 302-306, 1982.

[20] P. Trubat and C. Molins, "Rheological damping of slender rods," Pending to be Accept. Mar. Struct.

[21] J. Morison, "The force distribution exerted by surface waves on piles," 1953.

[22] G. M. Paredes, J. Palm, C. Eskilsson, L. Bergdahl, and F. T. Pinto, "Modelação Numérica de Sistemas de Amarração para Conversores Flutuantes de Energia das Ondas," pp. 41-48, 2013.

[23] A. Robertson et al., "Definition of the Semisubmersible Floating System for Phase II of OC4," 2014.

[24] E.-J. de Ridder, W. Otto, G.-J. Zondervan, F. Huijs, and G. Vaz, "Development of a Scaled-Down Floating Wind Turbine for Offshore Basin Testing," in Volume 9A: Ocean Renewable Energy, 2014, p. V09AT09A027.

[25] R. Kimball, M. J. Fowler, A. J. Goupee, E.-J. de Ridder, and J. Helder, "Wind/Wave Basin Verification of a Performance-Matched Scale-Model Wind Turbine of a Floating Offshore Wind Turbine Plattform," in Proceedings of the ASME 2014 33rd International Conference on Ocean, Offshore and Arctic Engineering, 2014, pp. 1-10.

[26] K. S. Chakrabarti, Handbook of offshore engineering, vol. 1. 2005.

[27] J. Jonkman, S. Butterfield, W. Musial, and G. Scott, "Definition of a 5-MW reference wind turbine for offshore system development," Contract, no. February, pp. 1-75, 2009. 